Review

\title{
Polysaccharides for tissue engineering: Current landscape and future prospects
}

\author{
Armen Tchobanian ${ }^{\mathrm{a}}$, Hans Van Oosterwyck ${ }^{\mathrm{b}}$, Pedro Fardim ${ }^{\mathrm{a}, *}$ \\ ${ }^{\text {a }}$ Chemical Engineering for Health \& Care, Bio\&Chemical Systems Technology, Reactor Engineering and Safety, Department of Chemical Engineering, KU Leuven, Belgium \\ ${ }^{\mathrm{b}}$ Biomechanics Section, Department of Mechanical Engineering, KU Leuven, Belgium
}

\section{A R T I C L E I N F O}

\section{Keywords:}

Polysaccharides

Tissue engineering

Regenerative medicine

Extracellular matrix

Biomaterials

Biopolymers

Topochemical engineering

\begin{abstract}
A B S T R A C T
Biological studies on the importance of carbohydrate moieties in tissue engineering have incited a growing interest in the application of polysaccharides as scaffolds over the past two decades. This review provides a perspective of the recent approaches in developing polysaccharide scaffolds, with a focus on their chemical modification, structural versatility, and biological applicability. The current major limitations are assessed, including structural reproducibility, the narrow scope of polysaccharide modifications being applied, and the effective replication of the extracellular environment. Areas with opportunities for further development are addressed with an emphasis on the application of rationally designed polysaccharides and their importance in elucidating the molecular interactions necessary to properly design tissue engineering materials.
\end{abstract}

\section{Introduction}

With the aim of generating a suitable replacement for the biological functions of damaged tissues and organs, tissue engineering has become a rapidly expanding multidisciplinary field of research over the past few decades. Although many clinical applications have been developed (Laschke \& Menger, 2016; Place, Evans, \& Stevens, 2009), there remain significant limitations to the types of tissue substitutes that may be used, with a variety of materials and manufacturing approaches being developed and assessed to address these issues. Though these tissue engineering scaffolds are being designed and applied to a variety of tissue types, the same overarching goal and its associated challenges exist: to effectively mimic the structure and functions of the extracellular environment being replaced. The scaffolds must provide suitable mechanical and chemical cues in order to direct the appropriate cell behaviour to achieve the regeneration and replacement of the necessary biological functions (Frantz, Stewart, \& Weaver, 2010; Martínez-Calderon et al., 2016; O’Brien, 2011; Place et al., 2009). To this end, the extracellular matrix (ECM) of the relevant site of implantation is the ideal template in designing an effective scaffold.

As a major player in the regenerative process, the ECM provides many biological cues that direct cell migration, adhesion, and differentiation, while being degraded and reconstructed as needed (Crowder, Leonardo, Whittaker, Papathanasiou, \& Stevens, 2016; Curtis, Dalby, \& Gadegaard, 2006; Hutmacher, 2010; O’Brien, 2011). Naturally, many materials used for these bioactive scaffolds are designed as analogs of ECM components, while many polysaccharide materials naturally present some analogous structures and functions to many of said components, as the ECM is predominantly made up of proteoglycans, glycosaminoglycans, glycoproteins and glycolipids (Hynes \& Naba, 2012; Hynes, 2009; Naba et al., 2016; Russo \& Cipolla, 2016). Along with the similarity to ECM components, the significance of glycan moieties as biomolecular cues (Dwek, 1996; Marth \& Grewal, 2008; Johnson, Jones, Ryan, \& Cobb, 2013; Russo \& Cipolla, 2016; Wang, 2014) and the combinatorial possibilities of carbohydrates (Wang, 2014) establish polysaccharides as a key player in the design of biomaterials for tissue engineering.

The immense structural and functional diversity of polysaccharides, in combination with the abundance and renewability of their sources, have found them applications in a wide variety of fields. Owing to their favourable characteristics such as biocompatibility and biodegradability, in combination with their structural and functional parallels to the extracellular matrix, the extensive polysaccharide library is gaining increasing interest within the tissue engineering field. Though the current approaches and applications of polysaccharides satisfy many of the properties necessary to achieve the desired cellular responses, they are not without flaws. This review aims to provide a perspective of the recent use of polysaccharides specifically within the tissue engineering field, followed by an assessment of the limitations of currently implemented approaches, and the associated enduring opportunities for

\footnotetext{
* Corresponding author.

E-mail address: pedro.fardim@kuleuven.be (P. Fardim).
} 


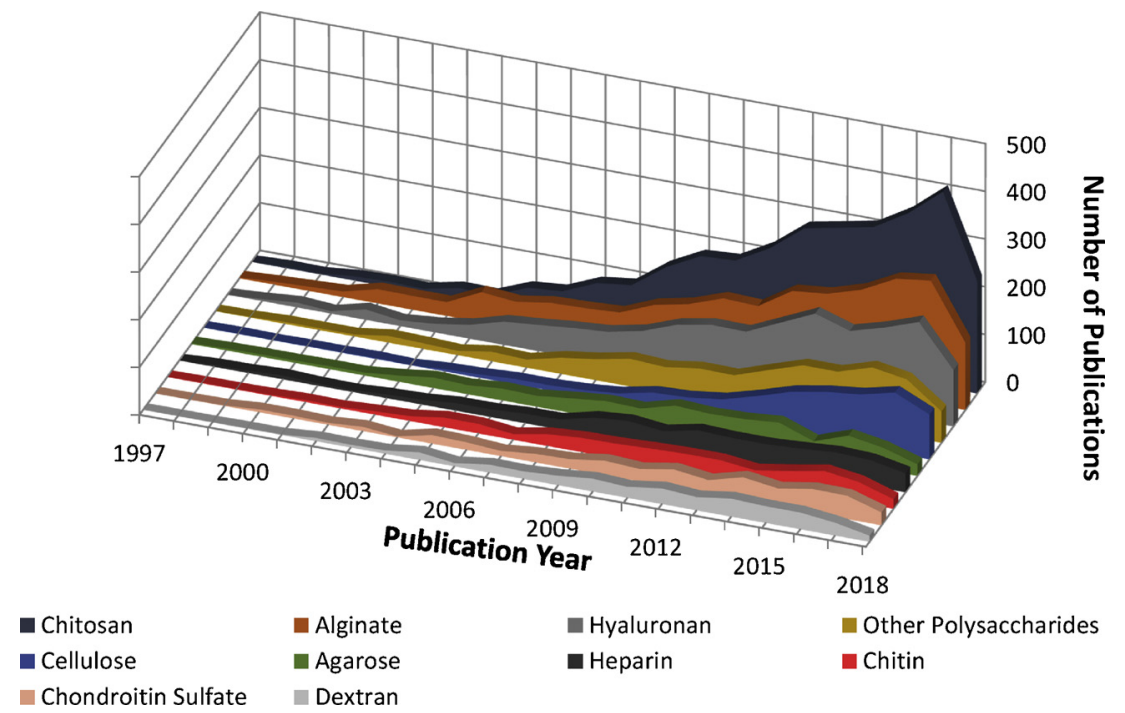

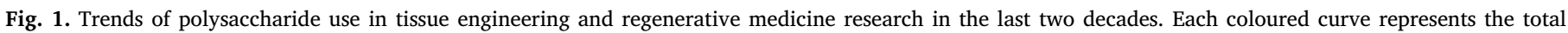
publication count per year for the associated polysaccharide. Data retrieved from Web of Science database in July 2018.

future development.

\section{Current state of the field}

Over the past few years there has been an increasing interest in the application of polysaccharide materials in the field of tissue engineering. To help illustrate this, Fig. 1 shows the number of papers published in the last two decades that have examined the use of polysaccharides in tissue engineering or regenerative medicine, separated by the main component used. As can be seen, while there is an increasing trend in the number of publications for tissue engineering in general, there are a handful of polysaccharides that have been given the greatest attention by the academic research community; namely chitosan, alginate, hyaluronan, and cellulose. To further assess the current scientific landscape, and leveraging the same set of bibliographic data used to generate Fig. 1 (ca. 11,000 articles), a bibliometric analysis was performed.

The entire set of publication data was downloaded from the Web of Science database (e.g. titles, abstracts, authors, citations, keywords) and processed using VOSviewer (van Eck \& Waltman, 2010, 2014) to extract and visualise relevant keywords from the dataset by using its text mining capabilities. The extracted set of keywords were filtered to avoid repetition of terms (i.e. plurals, hyphenated terms, and abbreviations), and the 100 most relevant terms were used to generate a keyword co-occurrence map, as shown in Fig. 2. The larger the size of a keyword on the map, the more frequently it occurs in the assessed publications, and the thicker the link between two terms, the more frequently they co-occur in publications. Additionally, the proximity, clustering, and colouring of each term on the map is determined based on their co-occurrence.

While the coloured clusters identify four different groups, these groupings should be interpreted carefully as each term cannot be shared between clusters, and the entire set of terms are highly interrelated. However, what can be seen is that the two largest clusters involve, in general, materials-related terms (red), and tissue-related terms (green), with the two smaller clusters involving a combination of terms falling in-between. Of greater utility, the state of the field and the focus of polysaccharide applications in tissue engineering can be seen at a glance on this co-occurrence map. Terms involving hydrogels, in vitro studies, bone tissue engineering, and cartilage tissue engineering are clearly prevalent and abundant, while terms involving physical or chemical modifications are lacking. Additionally, all the previously identified polysaccharides in Fig. 1, apart from dextran, appear in this network. Furthermore, and reinforcing the previous observations, the four most frequently occurring polysaccharides are chitosan, alginate, hyaluronic acid, and cellulose. In Fig. 2A-D, the co-occurrence networks of these prominently used polysaccharides can be seen, underlining their use in various manufactured forms, in combination with other components, and for different applications.

The dataset was also analysed using the R-package bibliometrix (Aria \& Cuccurullo, 2017) to examine keyword growth of prominent terms over the study period. These terms were split into categories including the polysaccharides applied, the manufactured form of the scaffold, the intended application, non-carbohydrate components, and cell behaviour (Fig. S1A-E).

Below, these prominently used polysaccharides, as well as some of those less frequently applied, will be independently examined in their methods of preparation, analysis, and application in the field in recent years. They will then be assessed on the basis of a number of common practices that have developed in this area of research, as highlighted in Fig. 2, followed by suggested approaches to address areas needing improvement.

\subsection{Chitosan}

Obtained through the deacetylation of chitin (poly $(\beta-(1 \rightarrow 4)-N$ acetyl-D-glucosamine)), the second most abundant natural polymer after cellulose (Rinaudo, 2006; Younes \& Rinaudo, 2015), chitosan is a linear polysaccharide consisting of randomly distributed D-glucosamine and $N$-acetyl-D-glucosamine residues (Fig. 3). While the main sources of chitin are the exoskeletons of arthropods or crustaceans such as crabs and shrimps, it can also be produced in the cell walls of some fungi and yeast (Cardoso, Costa, \& Mano, 2016; Lodhi et al., 2014; Younes \& Rinaudo, 2015). In the case of crustaceans, chitin is extracted following the deproteinisation, demineralisation, and occasionally depigmentation of their shells. While this form of the polymer has found its uses in many applications, including as a biomaterial in tissue engineering (Wan \& Tai, 2013; Younes \& Rinaudo, 2015), it is most frequently deacetylated to produce chitosan, which is soluble in mild acidic aqueous solutions, and is considered as such once the degree of deacetylation, i.e. the fraction of D-glucosamine units, is greater than $50 \%$.

The introduction of amino functional groups through this deacetylation, in combination with the available hydroxyl groups, and their distribution along the backbone, provides chitosan with many of its beneficial physico-chemical, and thus biological properties (NilsenNygaard, Strand, Vårum, Draget, \& Nordgård, 2015). Furthermore, 

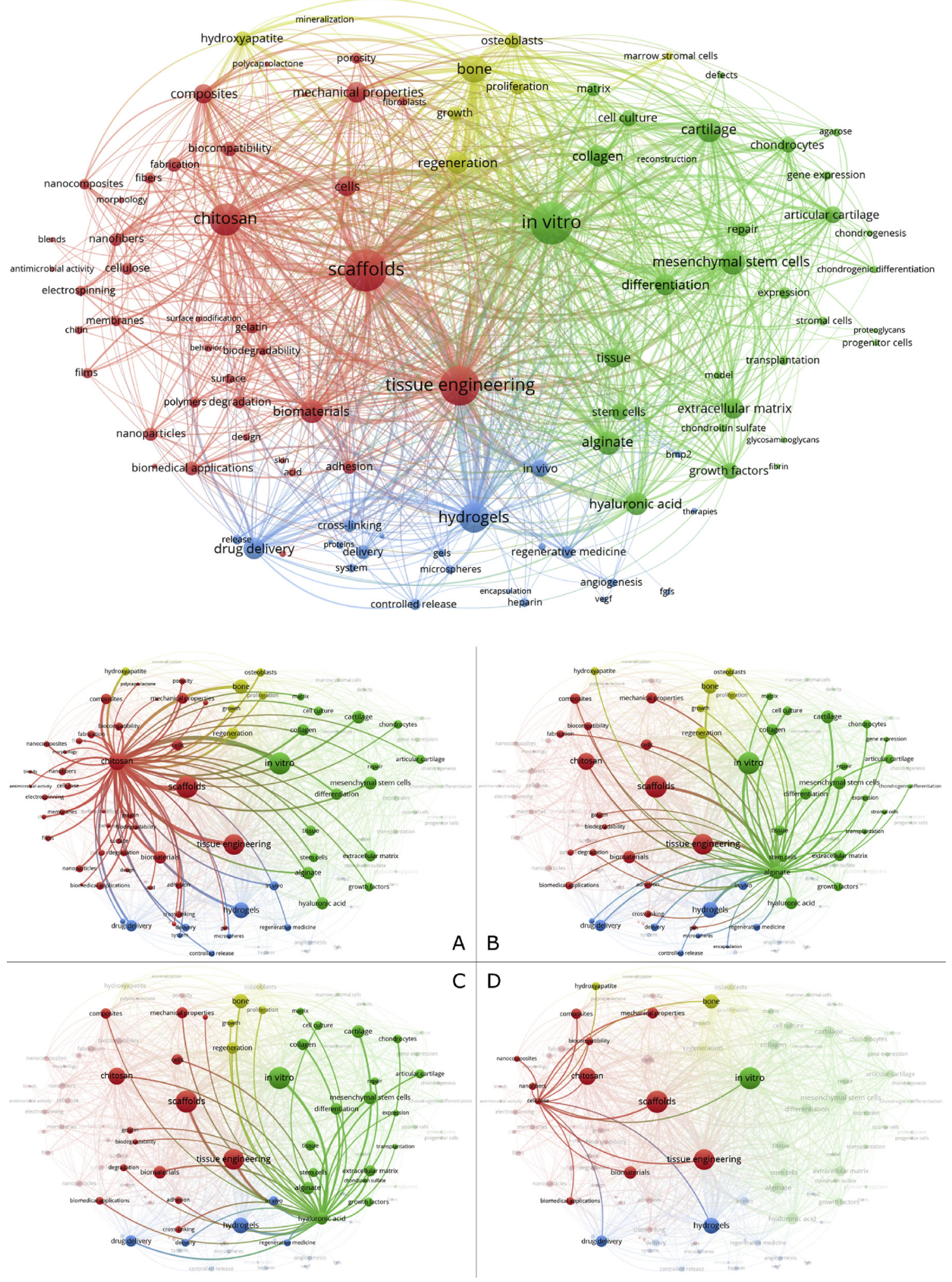

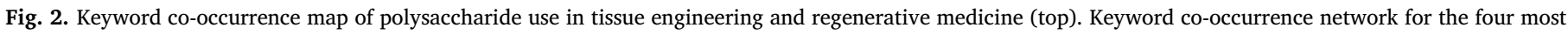
frequently applied polysaccharides (bottom): chitosan (A), alginate (B), hyaluronan (C), and cellulose (D).

being one of the few natural polycationic polysaccharides permits chitosan to have many electrostatic interactions that can be leveraged for both the production of biomaterials (such as in layer-by-layer polyelectrolyte assemblies), as well as for interesting opportunities for the material in a physiological environment, where most biomolecules are anionic. This, in combination with properties such as its biocompatibility, biodegradability, cell adhesiveness and antimicrobial activity (Cardoso et al., 2016; Rodríguez-Vázquez, Vega-Ruiz, RamosZúñiga, Saldaña-Koppel, \& Quiñones-Olvera, 2015; Younes \& Rinaudo, 2015), makes chitosan a suitable candidate for tissue engineering 


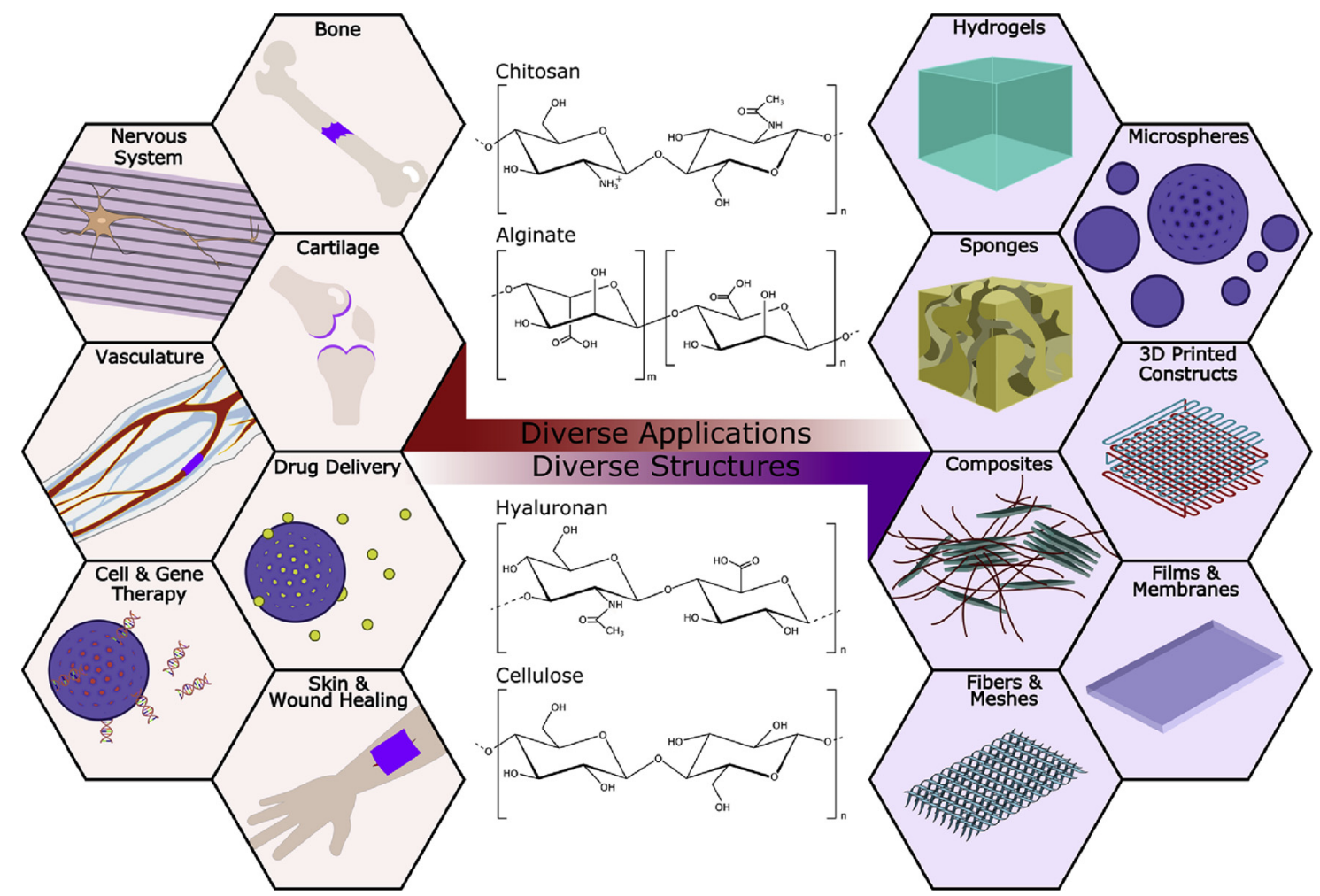

Fig. 3. Examples of polysaccharide-based scaffold formulations (right) and applications in tissue engineering (left). The chemical structures of chitosan, alginate, hyaluronan, and cellulose are included in the centre.

applications. With its widespread use in the field, some examples of the applications of this versatile polysaccharide in recent studies will be presented and discussed. Being a naturally derived compound, though not unique to chitosan, its sourcing and processing is of considerable importance to its uniformity, efficacy, as well as safety as a biomaterial.

\subsubsection{Material sourcing, processing, and derivatisation/modification}

Though typically sourced from crustacean shells, imparting a degree of variability and introducing the potential for impurities in the product, many studies in the field of tissue engineering simply apply the use of chitosan off-the-shelf (OTS), and without further purification, fractionation, or modification. Of course, while this is not true for all studies, it is the most prevalent approach to chitosan use within the field. Where this is not the case, purification of the chitosan product is either carried out via re-precipitation (Oliveira et al., 2016; Silva, Custódio, Reis, \& Mano, 2016; Wang et al., 2016), filtration (Bierhalz \& Moraes, 2016; Huang et al., 2016; Kim, Kawai, Wang, \& Yang, 2016; Zeng et al., 2016), or dialysis (Bernstein-Levi, Ochbaum, \& Bitton, 2016; Hayami, Waldman, \& Amsden, 2016). An additional step that can be carried out to further control the uniformity of the chitosan prior to further modification is the complete deacetylation of the product (Zeng et al., 2016). Derivatives are typically prepared to aid in either the solubility of chitosan in water, for example with carboxymethyl-chitosan (Fan et al., 2017; Gu et al., 2016; Huang et al., 2016; Zeng et al., 2016) and glycol-chitosan (Hayami et al., 2016), or to aid in the manufacture of the scaffolding, such as with methacrylated chitosan for UV crosslinking (Hayami et al., 2016), lactide for chemical crosslinking, or a combination of systems (Kim, Kawai et al., 2016). While normally applied in that manner, these derivatives have been shown to have other impacts as well. For example, where an increasing carboxymethyl-chitosan content improved hemocompatibility (Zeng et al., 2016), or the intermediate oligosaccharides arising from the degradation of chitosan could stimulate the proliferation of glial cells (Wang et al., 2016). Other components can also be attached to or combined with the polysaccharide when designing the scaffolds, to further tailor the physico-chemical properties and the bioactivity of the materials.

\subsubsection{Scaffold composition, preparation and intended applications}

Chitosan can be prepared into scaffolds either with or without additional components to enhance or alter the physical or chemical properties of the scaffolding (Table 1). These can include other polysaccharides such as alginate (Bierhalz \& Moraes, 2016), cellulose (Belluzo, Medina, Cortizo, \& Cortizo, 2016), and chondroitin sulfate (Hayami et al., 2016); synthetic polymers such as polyacrylamide (Yang, Wang, Yang, Shen, \& Wu, 2016) or polyvinyl acetate (Zeng et al., 2016); proteins such as gelatin (Ng, Yeong, \& Naing, 2016) and collagen (Sánchez-Sánchez et al., 2016); inorganic materials like hydroxyapatite for bone applications (Fan et al., 2016; Przekora, Benko, Blazewicz, \& Ginalska, 2016); and other forms of chitosan itself, such as the use of chitosan microspheres to improve the compressive modulus of the material (Fan et al., 2017). These materials are then formed into scaffolding, most frequently by crosslinking alone or in combination with another method of preparation, for instance before (Fan et al., 2016; Wang et al., 2016) or after (Reed et al., 2016) freeze drying, and following extrusion printing (Gu et al., 2016; Huang et al., 2016) or electrospinning (Zeng et al., 2016). This crosslinking is typically carried out either through UV exposure, using methacrylated derivatives (Hayami et al., 2016; Kim, Kawai et al., 2016), the addition of a photoinitiator (Yang et al., 2016), or through the addition of crosslinkers such as genipin (Silva, Custódio et al., 2016), gluteraldehyde (Kil'deeva et al., 2016), or EDC/NHS (Fan et al., 2016). Chitosan can also be embedded inside another matrix, such as alginate that has been crosslinked through the addition of $\mathrm{CaCl}_{2}$ (Bierhalz \& Moraes, 2016; Gu et al., 2016; Huang et al., 2016), and, as a polycation, can be used in the formation of polyelectrolyte complexes via layer-by-layer deposition (Oliveira et al., 2016; Silva, Custódio et al., 2016).

These scaffolds can then be improved in their bioactivity, namely their cell adhesiveness and influence on cell behaviour. Through the addition of molecules such as fibrinogen (Kim, Kawai et al., 2016), fibronectin (Silva, Custódio et al., 2016), or the RGD (Arg-Gly-Asp) 


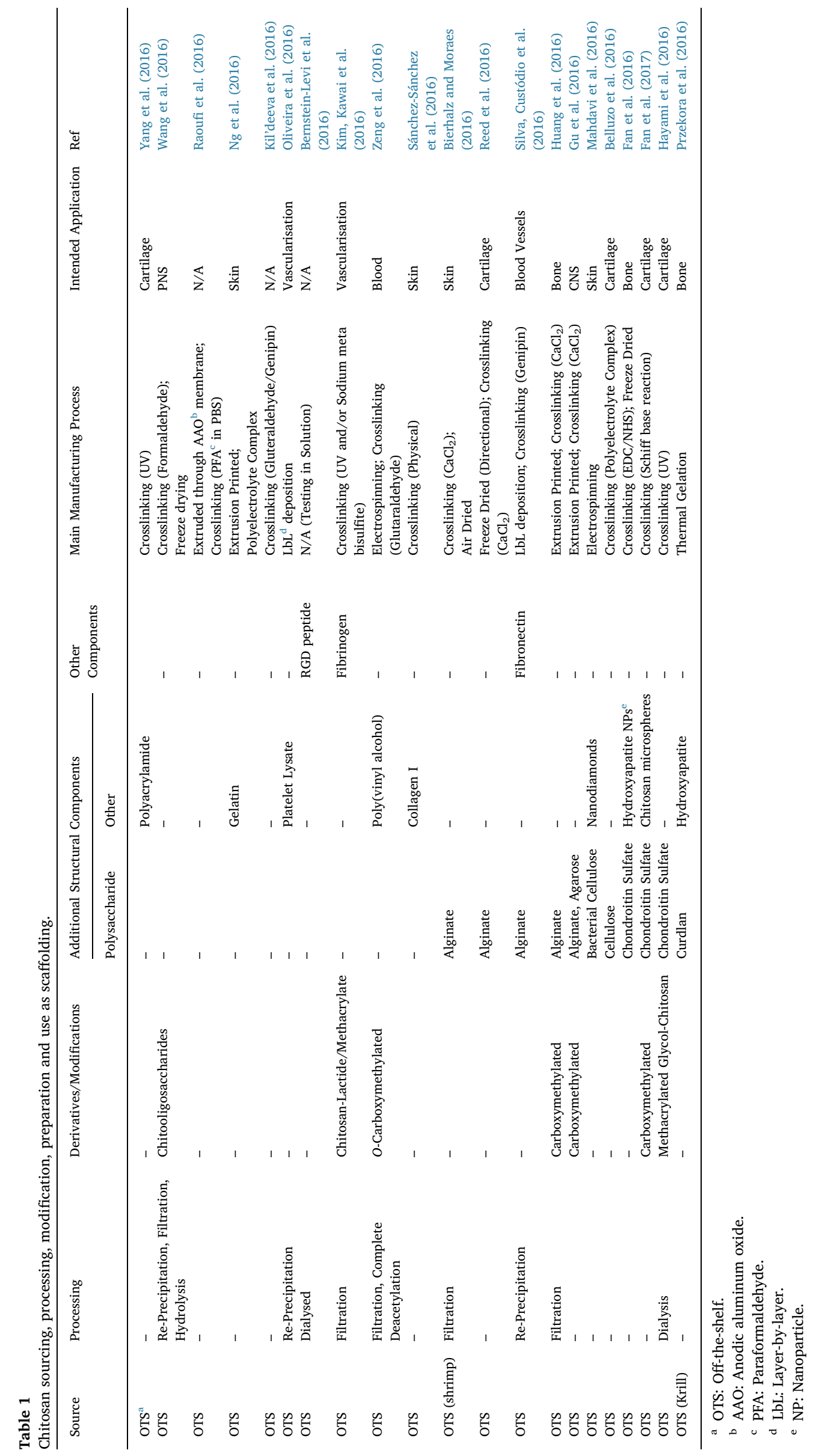


peptide sequence (Bernstein-Levi et al., 2016), a sequence in fibronectin involved in integrin binding, cell attachment to these materials can be improved. Cell behaviour and the binding of growth factors can also be mediated by coupling other biological components, for example, the inclusion of platelet lysates to stimulate the formation of neovasculature (Oliveira et al., 2016). Once formed, these chitosan-based biomaterials find their application as scaffolding primarily for skin and wound healing (Bierhalz \& Moraes, 2016; Mahdavi, Mahmoudi, Rezaie Anaran, \& Simchi, 2016; Ng et al., 2016; Sánchez-Sánchez et al., 2016), cartilage (Belluzo et al., 2016; Fan et al., 2017; Hayami et al., 2016; Reed et al., 2016; Yang et al., 2016), bone (Fan et al., 2016; Huang et al., 2016; Przekora et al., 2016) and vasculature (Kim, Kawai et al., 2016; Oliveira et al., 2016; Silva, Custódio et al., 2016), as well as for other tissues including the peripheral (Wang et al., 2016) and central (Gu et al., 2016) nervous systems. Examples of these and various other chitosan-based scaffolds, their method of preparation, and their intended applications can be found in Table 1 .

\subsection{Alginate}

A natural polysaccharide component of seaweeds, typically extracted from brown algae, and an exopolysaccharide of some bacteria, alginate is an anionic polymer containing blocks of either alternating or consecutive $(1 \rightarrow 4)$-linked $\beta$-D-mannuronic acid and $\alpha$-L-guluronic acid residues, known as the $\mathrm{M}$ and $\mathrm{G}$ blocks, respectively (Cardoso et al., 2016; Lee \& Mooney, 2011; Sun \& Tan, 2013). Commercially available alginate is extracted from algae by alkaline extraction, followed by filtration and precipitation with calcium or sodium chloride, and is then typically further processed to a water-soluble sodium alginate powder (Cardoso et al., 2016; Lee \& Mooney, 2011). With the possibility of extraction from many species of algae, for example Laminaria hyperborean, Laminaria digitata, and Laminaria japonica, alginates can differ in the length of their M, G, and alternating blocks as well as their residue content (Cardoso et al., 2016; Lee \& Mooney, 2011; Pawar \& Edgar, 2012). Unsurprisingly, this variability in composition, block length, and sequence will affect the physical and chemical properties of alginate and the materials produced from it. The second most-widely used polysaccharide in the field after chitosan, and touting many beneficial properties such as biocompatibility, tunable hydrophilicity and $\mathrm{pH}$ dependent anionic nature, coupled with its mild gelation conditions and ease of processing (Cardoso et al., 2016; Sun \& Tan, 2013), alginate finds many opportunities within the field. However, also being a naturally derived compound, its sourcing and processing remain critical aspects of its use as a biomaterial for tissue engineering scaffolds.

\subsubsection{Material sourcing, processing, and derivatisation/modification}

In addition to the degree of variability and potential for impurities already present in natural products, alginate, with its inherent irregularity of residue and block content, receives a similar treatment in recent tissue engineering studies as was the case with chitosan, being applied off-the-shelf. Although, as shown in Table 2, with alginate there is even less purification performed and modifications being applied. Similarly, while some studies filter (Ning, Xu, Chen, \& Schreyer, 2016) or clean (Akkineni et al., 2016) the material prior to use, it is not the norm, and none of the examined cases fractionated the purchased alginate. Moreover, only three of the alginate-based studies mention $\mathrm{G}$ or $\mathrm{M}$ block content, and out of those only one study assessed and discussed this content and its impact on the degree of substitution of their material (Scognamiglio et al., 2016).

Concerning the derivatives prepared, sulphated alginate was produced in order to mimic the binding affinity of heparan sulfate for growth factors (Ruvinov, Freeman, Fredo, \& Cohen, 2016). Alginate was also coupled to dopamine via carbodiimide chemistry in order to improve cell adhesion (Scognamiglio et al., 2016). A third study, by applying EDC/NHS coupling, attached bone formation peptide-1 (BFP1) to alginate, to improve the regeneration of bone (Heo et al.,
2017). Following the desired preparation of alginate, it can be formed into scaffolds, modifying the composition as necessary to tailor its properties.

\subsubsection{Scaffold composition, preparation and intended applications}

Though easily and frequently formed into a hydrogel on its own through ionic crosslinking with calcium ions, the blending of alginatebased scaffolding with other components can be used to improve its mechanical or biological properties (Table 2). As seen in the previous section, alginate is frequently combined with chitosan (Bierhalz \& Moraes, 2016; Gu et al., 2016; Huang et al., 2016; Reed et al., 2016), and can take advantage of the cationic nature of chitosan to form, for example, polyelectrolytic materials through layer-by-layer deposition (Silva, Custódio et al., 2016). Alginate has also been combined with other polysaccharides such as gellan gum to improve its properties for extrusion printing (Akkineni et al., 2016) as well as hyaluronan, which, rather than being used as a structural component in the scaffold, was released from the prepared alginate structure to promote wound healing (Scognamiglio et al., 2016). Other materials combined with alginate to produce scaffolds include self-assembling peptides (Çelik, Bayram, Akçapınar, Türk, \& Denkbaş, 2016), gelatin (Pan, Song, Cao, \& Wang, 2016), acrylamide (Giammanco, Carrion, Coleman, \& Ostrowski, 2016), as well as both silver (Correia et al., 2016) and gold (Ruvinov et al., 2016) nanoparticles. Additionally, since alginate on its own poorly promotes cell attachment (Cardoso et al., 2016; Pawar \& Edgar, 2012; Sun \& Tan, 2013), it is frequently coated or mixed with compounds to improve this property, employing the RGD peptide (Bernstein-Levi et al., 2016; Giammanco et al., 2016; Ning et al., 2016), and occasionally fibronectin or poly-L-lysine (Ning et al., 2016).

With all the necessary components now included to provide the required functionality, alginate is, as previously mentioned, commonly formed into a scaffold simply through ionotropic gelation by the addition of $\mathrm{CaCl}_{2}$ (Çelik et al., 2016; Ning et al., 2016; Pan et al., 2016; Ruvinov et al., 2016; Zhou, Liu, Yang, \& Ye, 2016), or via the same crosslinking mechanism in combination with other processing techniques. Among these are methods such as extrusion printing (Akkineni et al., 2016; Correia et al., 2016; Heo et al., 2017; Pan et al., 2016), freeze drying (Scognamiglio et al., 2016), and air drying (Giammanco et al., 2016). These alginate biomaterials find their use largely in cartilage (Çelik et al., 2016; Daly, Critchley, Rencsok, \& Kelly, 2016; Giammanco et al., 2016; Pan et al., 2016; Zhou et al., 2016) and bone (Akkineni et al., 2016; Correia et al., 2016; Heo et al., 2017) applications, and to a lesser degree as scaffolding in peripheral nervous system (Ning et al., 2016), vascular (Oliveira et al., 2016), and wound healing (Scognamiglio et al., 2016) applications.

\subsection{Hyaluronan}

A non-sulfated glycosaminoglycan and major component of the extracellular matrix, hyaluronan (or hyaluronic acid) is a linear polysaccharide made up of alternating $\beta$-( $1 \rightarrow 4)$-D-glucuronic acid and $\beta$ $(1 \rightarrow 3)$ - $N$-acetyl-D-glucosamine residues (Fig. 3 ) that is found in cartilage, synovial fluid, and skin (Cardoso et al., 2016; Muzzarelli, Greco, Busilacchi, Sollazzo, \& Gigante, 2012). Though hyaluronan can be extracted from animal sources such as rooster combs, bovine or fish vitreus humour or umbilical cords, it is produced on a large scale with bacterial sources such as Streptococcus equi and Streptococcus zooepidemicus (Cardoso et al., 2016; Muzzarelli et al., 2012; Rinaudo, 2008). Being part of the ECM, this polysaccharide is both naturally biocompatible and biodegradable in the human body, while also presenting bioactive domains or motifs involved in the various processes in the body such as tissue repair, proteoglycan organisation in the ECM, as well as various cell-mediating effects (Cardoso et al., 2016; Mero \& Campisi, 2014; Muzzarelli et al., 2012; Rinaudo, 2008). With its high viscoelasticity, high hydrophilicity, moisture retention, polyanionic nature, and as a natural component of the extracellular matrix, 


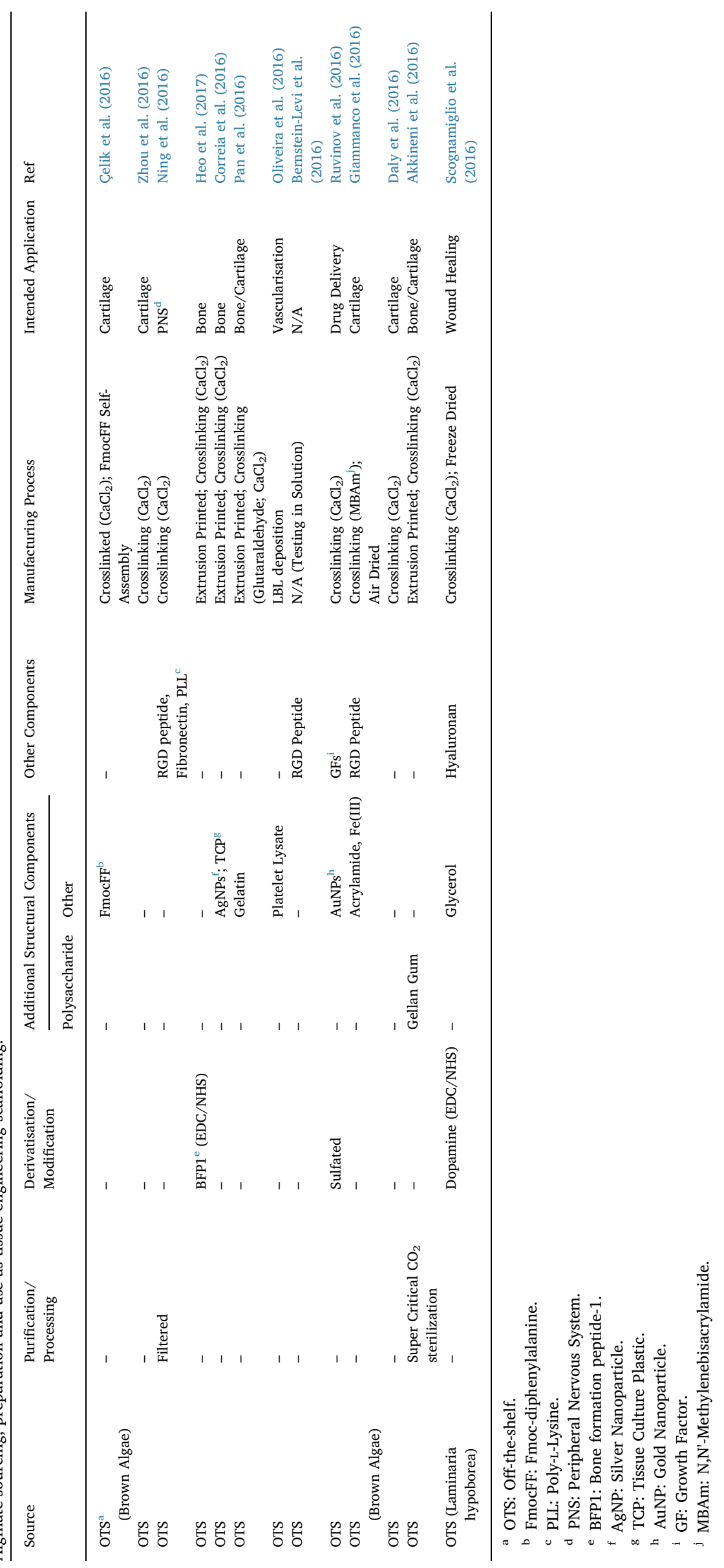




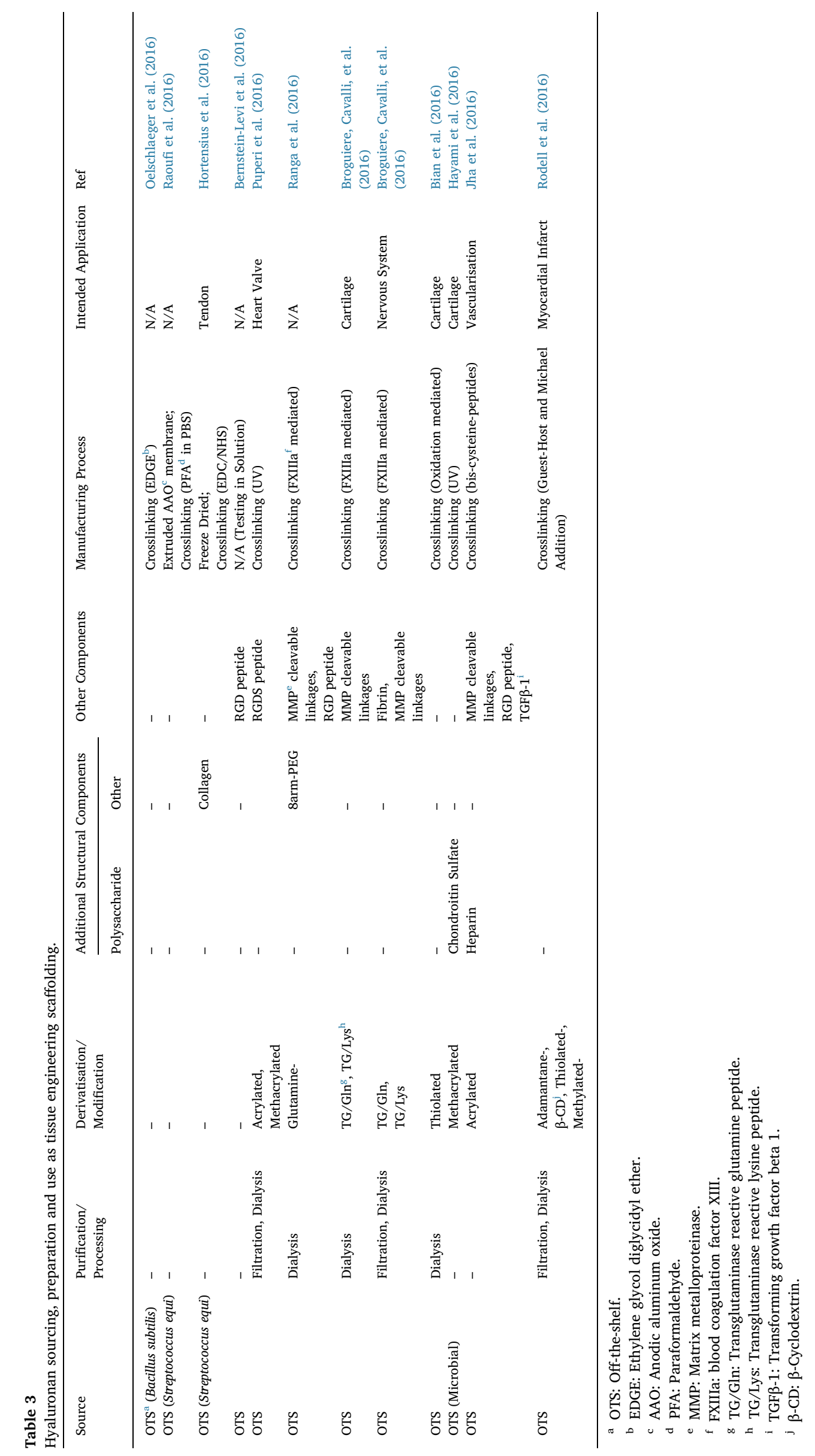


hyaluronan presents itself as an excellent biomaterial for tissue engineering. It follows that the sourcing, processing, and modification of hyaluronan are key to its efficacy as a scaffold.

\subsubsection{Material sourcing, processing, and derivatisation/modification}

The sources of hyaluronan in the examined studies (Table 3) are all off-the-shelf products, and, where identified, of bacterial origin. These products were frequently either dialysed (Bian et al., 2016; Broguiere, Cavalli, Salzmann, Applegate, \& Zenobi-Wong, 2016; Ranga, Lutolf, Hilborn, \& Ossipov, 2016) or both dialysed and filtered (Broguiere, Isenmann, \& Zenobi-Wong, 2016; Puperi et al., 2016; Rodell et al., 2016) to ensure purity of the samples in between all processing steps and modifications. The hyaluronan in the studies was also often further modified, with many different approaches being applied. The polysaccharide was acrylated for UV crosslinking (Puperi et al., 2016) or for Michael addition crosslinking (Jha et al., 2016; Rodell et al., 2016), methacrylated for UV crosslinking (Hayami et al., 2016; Puperi et al., 2016), and thiolated for oxidation-mediated (Bian et al., 2016) or Michael addition crosslinking (Rodell et al., 2016). It has also been coupled with adamantane and $\beta$-cyclodextrin for guest-host interactions to produce an initially soft and injectable hydrogel (Rodell et al., 2016). The functionalization of hyaluronan with transglutaminase substrate peptides containing either a reactive glutamine or lysine residue (Broguiere, Cavalli, et al., 2016; Broguiere, Cavalli, et al., 2016; Ranga et al., 2016), was even exploited to allow FXIIIa (blood coagulation factor XIII) mediated crosslinking, providing the resultant hydrogels with improved biocompatibility, gelling kinetics, and adhesion. The impacts of the chosen modifications of interest will be discussed in context of the properties of the designed scaffolds below.

\subsubsection{Scaffold composition, preparation and intended applications}

Though effective on its own, and used as such following crosslinking (Oelschlaeger, Bossler, \& Willenbacher, 2016; Raoufi et al., 2016), hyaluronan can be prepared into scaffolding with the addition of other materials to improve its properties and capabilities (Table 3). For instance, collagen can be introduced into the system to help produce a scaffold with a composition similar to the native extracellular matrix and help reduce the inflammatory response (Hortensius, Ebens, \& Harley, 2016). Other natural polysaccharides, such as the glycosaminoglycans chondroitin sulfate or heparin, can also be added to enhance cell behaviour (Hayami et al., 2016), or to sequester exogenous and endogenous growth factors (Jha et al., 2016), respectively. As with other materials, the RGD peptide sequence can be added to hyaluronan scaffolds to further improve cell attachment (Bernstein-Levi et al., 2016; Jha et al., 2016; Puperi et al., 2016; Ranga et al., 2016). The hyaluronan-based scaffolds were produced almost entirely through various crosslinking methods, with the exception of two studies where the materials were either first extruded through a membrane (Raoufi et al., 2016), or freeze dried (Hortensius et al., 2016). Notably, the use of a dual crosslinking approach employed both a shear-thinning guesthost interaction to allow injection of the hydrogel scaffold, and a secondary covalent crosslinking to stiffen in-situ (Rodell et al., 2016).

Of further interest, matrix metalloproteinase (MMP)-cleavable peptide crosslinks were used to confer a more cell-mediated degradation of the scaffold (Broguiere, Cavalli, et al., 2016; Broguiere, Cavalli, et al., 2016; Jha et al., 2016; Ranga et al., 2016), with one such study observing that slower degrading sequences promote the highest cell proliferation, survival and rapid blood vessel formation (Jha et al., 2016). Another study found, however, that there was no significant difference in cell behaviour between hydrogel scaffolds with and without these cleavable links, suggesting that this would incur an increased risk of the scaffold degrading prematurely (Broguiere, Cavalli, et al., 2016), while demonstrating a need for further assessment of the impact of enzyme-labile crosslinkers. Despite the prominence of crosslinking hyaluronan, and while allowing for a tunable scaffold that promotes good cell compatibility, it may also render its natural receptors and signalling motifs less available (Puperi et al., 2016), highlighting an additional consideration for the design of tissue engineering materials. Being a component of the natural cartilage, these scaffolds are applied predominantly for cartilage (Bian et al., 2016; Broguiere, Cavalli, et al., 2016; Hayami et al., 2016), while also finding use as materials for tendon (Hortensius et al., 2016), heart valve (Puperi et al., 2016), nervous system (Broguiere, Cavalli, et al., 2016), and vasculature (Jha et al., 2016) applications.

\subsection{Cellulose}

Commonly lauded as the most abundant renewable polymer in the world, cellulose is a linear polysaccharide consisting of $\beta$ - $(1 \rightarrow 4)$-linkedD-glucose units (Fig. 3), and is produced by many plants as well as some bacteria, fungi, and even some sea animals (e.g. tunicates) (Siqueira, Bras, \& Dufresne, 2010; Zhu et al., 2016). The content of the plantderived cellulose varies with the type of plant, and is typically found with a mixture of other compounds such as hemicelluloses, lignin, pectin, ash, and extractives, while the bacteria-derived variety, known as bacterial cellulose, is almost pure (Siqueira et al., 2010; Zhu et al., 2016). With the presence of its many hydroxyl groups, in combination with the linearity of the polymer backbone, cellulose chains form many inter- and intra-molecular hydrogen bonds. These contribute both to its ordered and crystalline structures, of which there are several different arrangements, as well as its insolubility in water and other common solvents (Siqueira et al., 2010; Zhu et al., 2016). Though its processability may be challenging, cellulose and its derivatives have found applications within the field of tissue engineering, being further supported by the existing and extensive history of both the chemical and physical processing and modification of cellulose.

\subsubsection{Material sourcing, processing, and derivatisation/modification}

In stark contrast to the previously covered materials, the majority of studies employing cellulose as a main scaffolding material in tissue engineering do not use off-the-shelf products. The polysaccharide is either produced using acetic acid bacteria such as Gluconacetobacter hansenii PJK (Khan et al., 2016) and (Glucon)acetobacter xylinum (Bonilla, Lopez-Sanchez, Gidley, \& Stokes, 2016; Lamboni, Li, Liu, \& Yang, 2016), followed by cleaning in an alkali solution, or from cotton linter pulp (Yang \& Han, 2016; You et al., 2016), following the extraction and purification procedures listed in Table 4. As discussed above with the previous three polysaccharides, however, the nature of the modifications applied to cellulosic materials in tissue engineering comes from a predominantly materials point-of-view as opposed to being driven by an intended biological functionality. Derivatives and forms of cellulose applied include cellulose nanocrystals (CNCs) to be used as a structural material to reinforce a softer phase (Yang \& Han, 2016; You et al., 2016), hydroxethyl cellulose for its water solubility, biodegradability, and structural similarity to GAGs (Khorshidi et al., 2016), quaternised cellulose for its thermogelling behaviour (You et al., 2016), and cellulose acetate for its amenability to the electrospinning process (Atila, Keskin, \& Tezcaner, 2016; Ye, Li, Chen, Zhan, \& Li, 2017).

Another cellulosic nanomaterial, cellulose nanofibrils (CNFs), also find a variety of promising applications in tissue engineering owing to their structural similarity to the native ECM and ability to form robust hydrogels (Kuzmenko, Karabulut, Pernevik, Enoksson, \& Gatenholm, 2018; Xu, Wang, Sandler, Willför, \& Xu, 2018). Similarly to CNFs, bacterial cellulose also benefits from many of the same properties by virtue of its naturally formed three dimensional nanofibrous network, and is further aided by its ease of production (Picheth et al., 2017; Torgbo \& Sukyai, 2018).

\subsubsection{Scaffold composition, preparation and intended applications}

Following purification and desired derivation of cellulose, it is then mixed with other materials, or with other forms of cellulose, in order to 


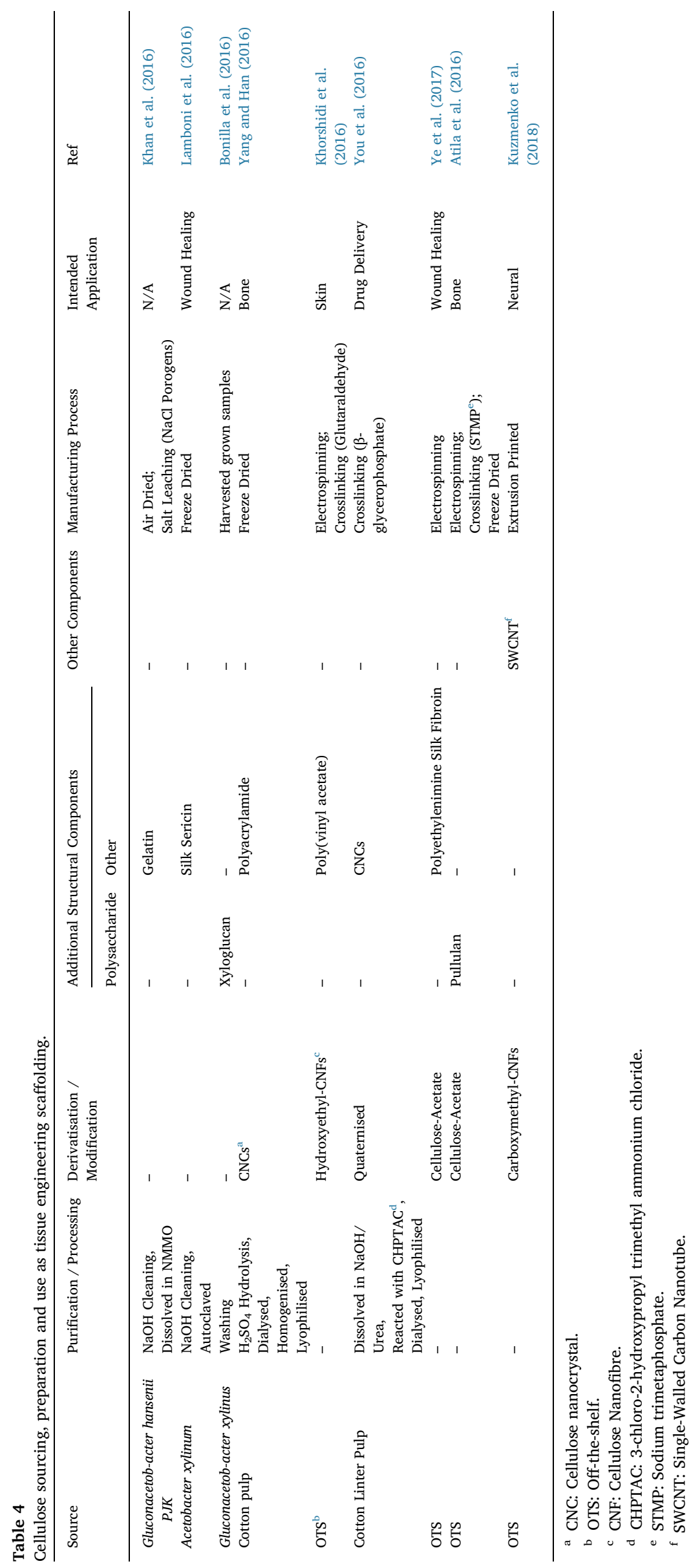


produce the necessary scaffold. To improve biocompatibility or cell viability and adhesion, cellulose was combined with gelatin (Khan et al., 2016), silk sericin (Lamboni et al., 2016), and silk fibroin (Ye et al., 2017). For improved mechanical properties, it could be coupled with xyloglucan to increase its extensional resistance and compressive modulus (Bonilla et al., 2016), with polyacrylamide to increase the scaffold elasticity (Yang \& Han, 2016), or with poly(vinyl acetate) for both improved durability and to allow electrospinning of the material (Khorshidi et al., 2016). The cellulose scaffolds were formed primarily by electrospinning (Atila et al., 2016; Khorshidi et al., 2016; Ye et al., 2017), as well as with a range of other techniques, including air drying with porogens (Khan et al., 2016), freeze drying (Lamboni et al., 2016; Yang \& Han, 2016), crosslinking (Atila et al., 2016; Khorshidi et al., 2016; You et al., 2016), 3D printing (Kuzmenko et al., 2018), or simply by harvesting a bacterial cellulose sample (Bonilla et al., 2016). It is also interesting to note that none of the examined studies of cellulosebased scaffolding included a cell-adhesion promoting biomolecule such as the RGD peptide or fibronectin. Similar to many of the previously discussed polysaccharides, cellulose is also able to confer cell-adhesive behaviour and other biological functionality without applying the naturally available ligands, indicating that their use may not be strictly necessary, and that an improved understanding of the chemistry and physics at play will be of critical importance to the design of improved tissue engineering scaffolds. While applied mainly for skin or wound healing (Khorshidi et al., 2016; Lamboni et al., 2016; Ye et al., 2017), these cellulosic scaffolds are also applied for bone tissue engineering (Atila et al., 2016; Yang \& Han, 2016), as injectable scaffolds allowing for drug delivery (You et al., 2016), and even as guidelines in the formation of neural networks when applied in their nanofibrillar form (Kuzmenko et al., 2018).

\subsection{Other polysaccharides}

The same analysis has been performed for other polysaccharides, and their sourcing and preparation as scaffolds can be found in Table S1. These polysaccharides include, among others: agarose, heparin, chondroitin sulfate, dextran, starch, gellan gum, pectin, carrageenan, pullulan, xanthan gum, fucoidan, and laminarin. While each of these polysaccharides and their properties will not be covered in detail in this review, their processing and preparation into scaffolds will be briefly discussed, highlighting selected studies of interest. Although we again find here the predominant use of un-modified off-the-shelf products and the use of derivatives to aid in processing and manufacturing scaffolds, some attractive properties were obtained through the use of a few modifications with potential for applications in the field.

In a study by Wu et al. (2016), dextran was modified with zwitterionic carboxybetaine moieties to achieve anti-fouling properties, preventing non-specific protein and cell adhesion, while simultaneously including both the RGD peptide motif to re-introduce cell adhesion, and collagenase-cleavable crosslinks to control the degradation of the hydrogel matrix. Combinations of biomimetic functionalities such as these could be potentially applied to design and control precise adhesive domains and degradation paths within a scaffold. Catecholamines have also been used to modify polysaccharides, as was done by Lee et al. (2016), where dopamine was conjugated onto a heparin backbone via EDC coupling, finding that the catechol moieties conferred protein adsorption, specifically of vitronectin, as well as cell adhesion, while also allowing the maintenance of embryonic stem cell cultures. They also assessed a combination system with the modified heparin and coimmobilised collagen I, finding a synergistic effect of pluripotent maintenance and stem cell adhesion. The analysis of various combinations of polysaccharide-protein and other glycoconjugate systems such as this will be pivotal in understanding the role of the many ECM constituents, the impact of the diverse array of glycan moieties that decorate them, and the considerable importance of glycobiology. Another system utilised a vinylsulfone-modified variant of dextran to allow the coupling of multiple biomolecules such as adhesive peptides and growth factors to assess the efficacy of these multifunctional surfaces (Noel et al., 2016). They observed that a combination of the adhesive RGD peptide and the vascular endothelial growth factor (VEGF) could promote the adhesion and selective proliferation of endothelial cells.

Chitin, though receiving less attention due to its poor solubility in aqueous solutions in its natural form, and most frequently being deacetylated into its more soluble form, chitosan, has also been applied in the field through its modification into more soluble derivatives. Aside from the addition of hydrophilic groups such as carboxymethyl-chitin and glycol-chitin in order to improve its solubility in water (Wan \& Tai, 2013), another approach involves the use of chitin-esters (SkołuckaSzary et al., 2016). One such example is the use of the diesters chitindihexanoate and chitin-dibutyrate, allowing solubility of the polysaccharide in common organic solvents and being easily processed into biocompatible porous structures for wound healing applications. The sulfation of polysaccharides can also be an interesting avenue, producing analogues of the naturally sulfated members of the ECM. For example, the application of sulfated levan exhibiting heparin-mimetic anticoagulant activity via thrombin inhibition (Erginer et al., 2016), and a carboxymethylglucose sulfate wound dressing which mimics the role heparan sulfate in inflammation and tissue repair (Papanas, Demetzos, Pippa, Maltezos, \& Tentolouris, 2016).

Some less frequently used polysaccharides, such as starch, are not typically used on their own as scaffolding owing to their unsuitable mechanical properties and difficulty in processing ( $\mathrm{Wu}$, Samanta, Srivastava, \& Hakkarainen, 2017). Starch is instead applied by being grafted with other polymers (Meimoun et al., 2017), reinforced as composites (Miculescu et al., 2017), or blended with other materials (Dong et al., 2018; Van Nieuwenhove et al., 2016). The components of starch have also been applied, for example, where amylopectin was used in a freeze dried ternary system, conferring greater porosity and larger pore sizes (Rajesh et al., 2016). Nanoformulations of starch are also gaining increased attention in the field, particularly when applied as nanofibers (Hemamalini \& Giri Dev, 2018; Liu, Gu, Hong, Cheng, \& Li, 2017). With their high specific surface area, porosity, and the similarity of their fibrous structure to ECM components, starch nanofibers have found applications from wound healing (Waghmare et al., 2018) to bone tissue engineering (Wu et al., 2017).

Though there are clearly studies involving polysaccharides modified for enhanced biomimetic activity as discussed in this section, the common practice of using un-modified off-the-shelf polysaccharides for the production of tissue engineering scaffolds remains a critical limitation in the progress of the field. To this end, the analysis of the physico-chemical properties of these polysaccharide-based scaffolds and its influence on their suitability in the intended biological setting will aid in determining the appropriate design needed to achieve the necessary bioactivity for a specific application.

\subsection{Material characterisation performed}

Aside from the modification and processing of polysaccharide-based tissue engineering scaffolds, the characterisation of its physico-chemical and biological properties are necessary for elucidating the impact of the design. From this sample set of studies, there exist some consistencies among the characterisations that are being performed. In terms of physical assessment, while the majority carry out morphological analysis, generally through SEM imaging, only half of the studies carry out either compressive or tensile mechanical testing on their scaffolds. For chemical analysis a similar situation is observed, with roughly half performing bulk or surface chemical characterisation through either FTIR or NMR, and occasionally XPS and XRD.

When it comes to examining other key factors including, but not limited to, the topography, rheology, degradability, contact angle and surface charge, the situation is observably lacking, with very few of the 
studies assessing these characteristics, and in some cases not at all. Concerning the biocompatibility and biological suitability, though many studies evaluate the initial attachment/viability or the proliferation of the cell line being tested, some essential aspects of scaffold performance are overlooked. Regarding cell behaviour, the effects of the scaffold on cell migration or invasion, and on cell differentiation or how the material modulates cell genetic/transcriptional expression (or other -omic studies), are not frequently studied. Furthermore, the hemocompatibility and immunocompatiblity of the scaffolding, its impact on protein adsorption, and its ability to induce the production or expression of extracellular matrix components are also essential factors that receive limited focus.

Naturally, this is not representative of every study as some of these properties may not be pertinent given the intent of the research, and as such it is necessary to take into account the aim and context of the study. For instance, many of these characterisations may not be relevant when the degradation products of chitosan are being assessed for their effects on stimulating nerve regeneration (Wang et al., 2016), where the behaviour of polysaccharide-peptide conjugates in solution are being assessed (Bernstein-Levi et al., 2016), when macrophages are being employed to assess the inflammatory response of the system (Belluzo et al., 2016), or when platelets are being used to examine the hemocompatiblity of a sample (Zeng et al., 2016). Nevertheless, even when excluding such cases, the physico-chemical characterisation and biological response of many of these polysaccharide-based tissue engineering scaffolds are often overlooked. The characterisation of these material properties and the elucidation of the impact they have via cellmaterial interactions in a physiological setting are essential to improving the design of these tissue engineering scaffolds and will be crucial in advancing the ability of these scaffolds to achieve the intended biological response and activity. This, in combination with the use of more rationally designed polysaccharides in scaffolds, will be vital to the development of more effective biomaterials. For this reason, only those studies that examined both material composition and its influence on cell fate will be covered in detail, with emphasis given to studies examining the in vivo capabilities of the designed scaffold.

\subsubsection{Cell-material interactions}

Studies that examined both the in vitro behaviour as well as the two most frequently assessed material characteristics, mechanical stiffness (or strength) and porosity, are reported here in order to provide a large enough sample size to give some perspective on the scope of these characteristics in current polysaccharide scaffold designs and their influence on cell-material interactions. In Table 5, the reported material characteristics and the observed effects of the manufacturing process on them can be seen, while the associated tissue of application, cell line studied, and biological effects of the mechanical properties and material design can be found in Table 6. Beginning with the mechanical properties of these materials, it can be seen that even with the purely polysaccharide based scaffolds their elastic moduli can range from a single $\mathrm{kPa}$ up to several hundred MPa, providing them with one of the crucial factors to be applicable as a suitable matrix for both soft tissue, such as the brain, up to cartilage and even cancellous bone (Amini, Laurencin, \& Nukavarapu, 2012; Butcher, Alliston, \& Weaver, 2009). Similarly, when it comes to the porosity and pore size, these scaffolds are able to cover the range necessary for the majority of cellular activities (Loh \& Choong, 2013), with values from 30\% to 95\% and 0.01 to $600 \mu \mathrm{m}$, respectively. Additionally, there exist in most cases a simple and reliable means of tailoring these properties.

When looking at the factors that influence these features, an increase in scaffold stiffness is typically acquired at the expense of pore size and porosity, and vice versa, with an increase in scaffold density and the strength of internal interactions providing the former, and the opposite in the latter. For instance, in most scaffold designs, increasing the concentration or fraction of one or more materials (Custódio, Reis, \& Mano, 2016; Kil'deeva et al., 2016; Rajesh et al., 2016; Silva, Pirraco et al., 2016), as well as through decreasing their molecular weight (Hayami et al., 2016; Kil'deeva et al., 2016; Skołucka-Szary et al., 2016) improves mechanical properties and decreases pore size and/or porosity. This outcome is also observed when increasing the crosslinking density of a scaffold, through the use of either more crosslinker (Kil'deeva et al., 2016; Pan et al., 2016), a longer crosslinking time (Giammanco et al., 2016; Huang et al., 2016), a stronger crosslinking method (e.g. glutaraldehyde vs. genipin) (Kil'deeva et al., 2016; Pan et al., 2016), or an increase in the degree of functionalisation of a group necessary for crosslinking (e.g. methacrylate) (Custódio et al., 2016; Hayami et al., 2016). Modifications in the manufacturing procedure itself can also be used to effectively alter these characteristics: the use of directional freeze drying increases compressive strength and aligns pores in the direction of freezing (Y. Zhang et al., 2016); when 3D printing, changing the orientation of successive layers confers an increased stiffness without influencing porosity (Pan et al., 2016); and, in an iron-coordinated alginate gel, the photochemical reduction of Fe(III) ions inside lowers stiffness and increases pore size by degrading the surrounding alginate matrix (Giammanco et al., 2016). Beyond having the capability to tailor the scaffolds to meet the requirements of the intended area of application, the influence of these changes on cell fate should also be evaluated, as it will aid in developing a mechanistic understanding on cell-material interactions which can be applied to further improve implant designs.

Many of the material properties and design choices in Table 5 were tested for their influence on cell behaviour (Table 6); however, of note is that neither the pore size, porosity, nor pore distribution were investigated in this manner. While essential for the diffusion of nutrients, waste, and oxygen, an adequate porous network also permits the cell migration and proliferation needed for the proper vascularisation and tissue ingrowth of a scaffold. Furthermore, it can direct cell behaviour and differentiation through mechanotransductive means; the presentation of receptors, sequestered growth factors and other soluble factors; as well as through gradients of porosity and pore size (Loh \& Choong, 2013). With regards to the mechanical and structural properties discussed above, the different scaffolds have varying reported cellmaterial interactions which, while a preliminary indication of the potential of one scaffold composition and manufacturing method in a chosen in vitro model, are difficult to compare directly. Drawing from this limited transferability of each result, it would be interesting to see the outcomes of comprehensive studies across multiple well-designed polysaccharide scaffolds assayed against a single in vitro or in vivo model.

What can be seen is that cell encapsulation is possible in hydrogel scaffolds, such as those cast or printed and crosslinked, for a wide variety of cell types (including primary cells) and materials. One study in particular compared the 2D and 3D culturing of Schwann cells on and in $\mathrm{Ca}^{2+}$ crosslinked alginate hydrogel finding that, while viability, proliferation, and fate were unaffected, cells tended to feel somewhat enhanced impacts of stiffness observed in the 2D environment once fully encapsulated in the same material (Ning et al., 2016). Of further note is that while many studies in the field have assessed the in vitro compatibility of their scaffolds and their capacity to regulate the cells in that context, which may provide an indication as to the suitability of the scaffold design in vivo, appropriate models are necessary to determine the actual applicability of these materials for tissue engineering applications; i.e. their ability to enhance the regeneration of tissue in the desired manner. To this end, in Table 6 it can be found that though these studies use either cell lines or an appropriate primary cell culture as models for testing their scaffolds, which are not necessarily representative of the in vivo environment, fewer in vivo studies have been performed.

Of interest among the studies, a dual-layer chitosan-lactide hydrogel designed by Kim, Kawai et al. (2016) was tested for its capability to improve vascular development and blood perfusion in a mouse model of hind-limb ischemia. The scaffold consisted of a soft top layer for 


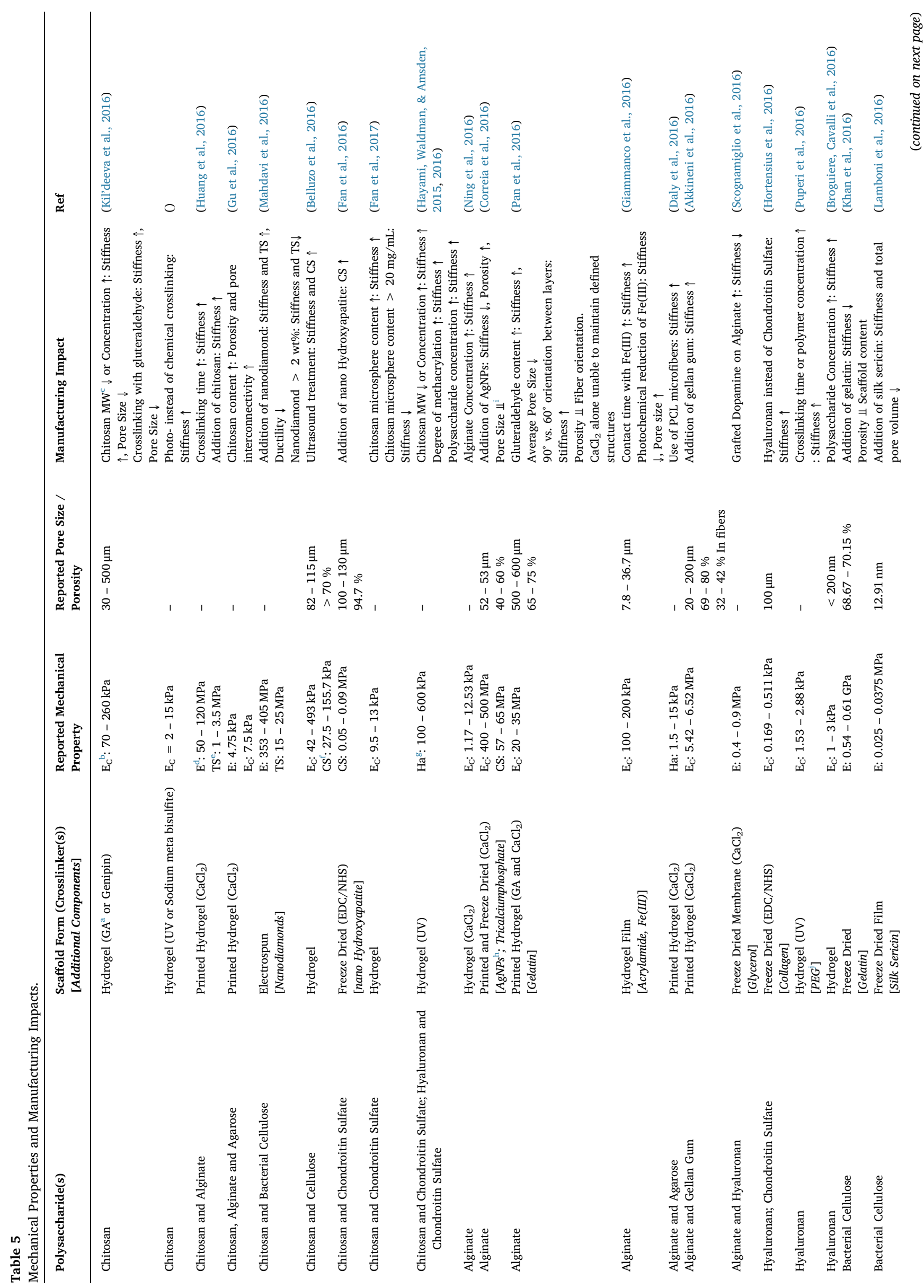




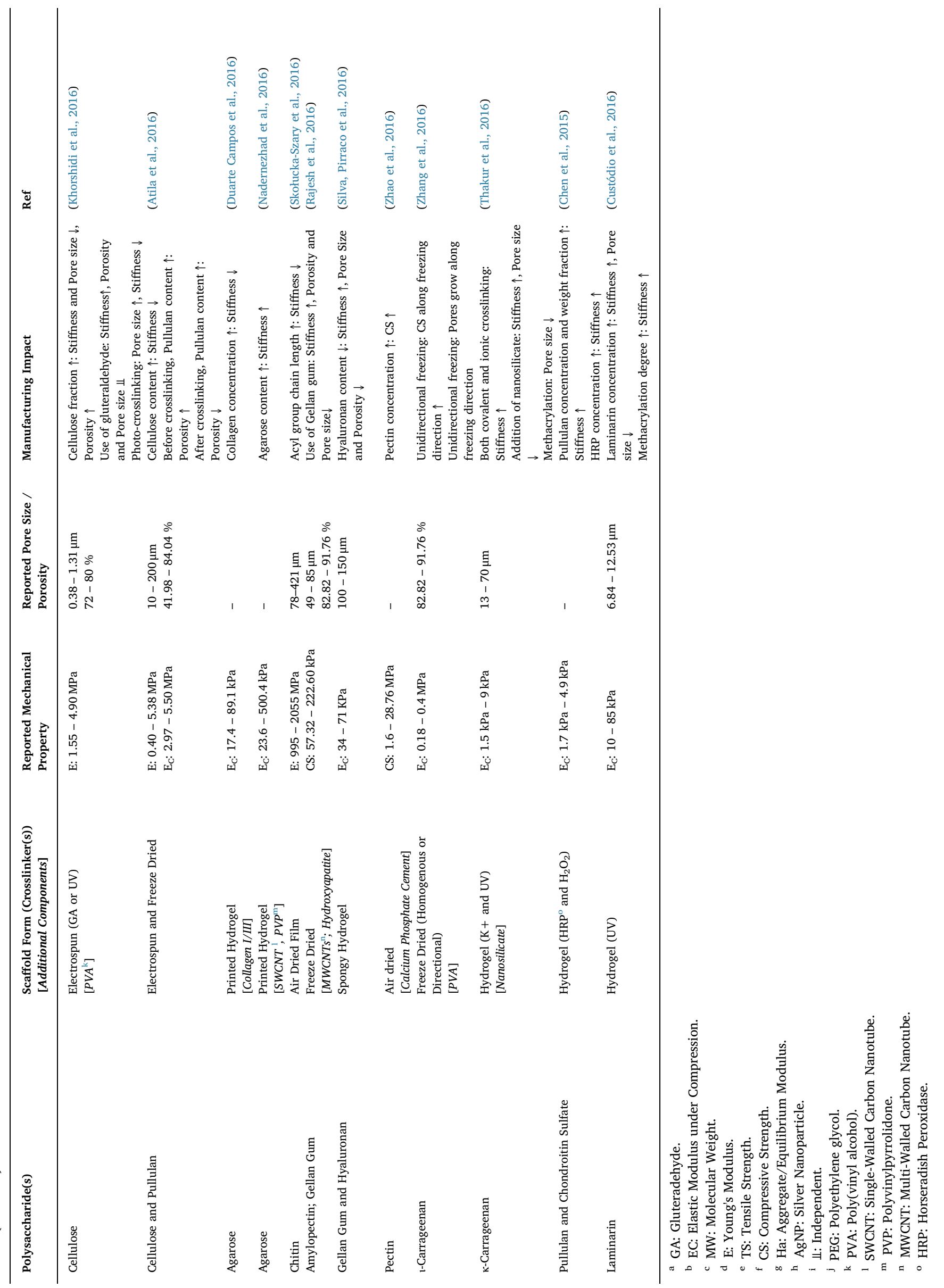



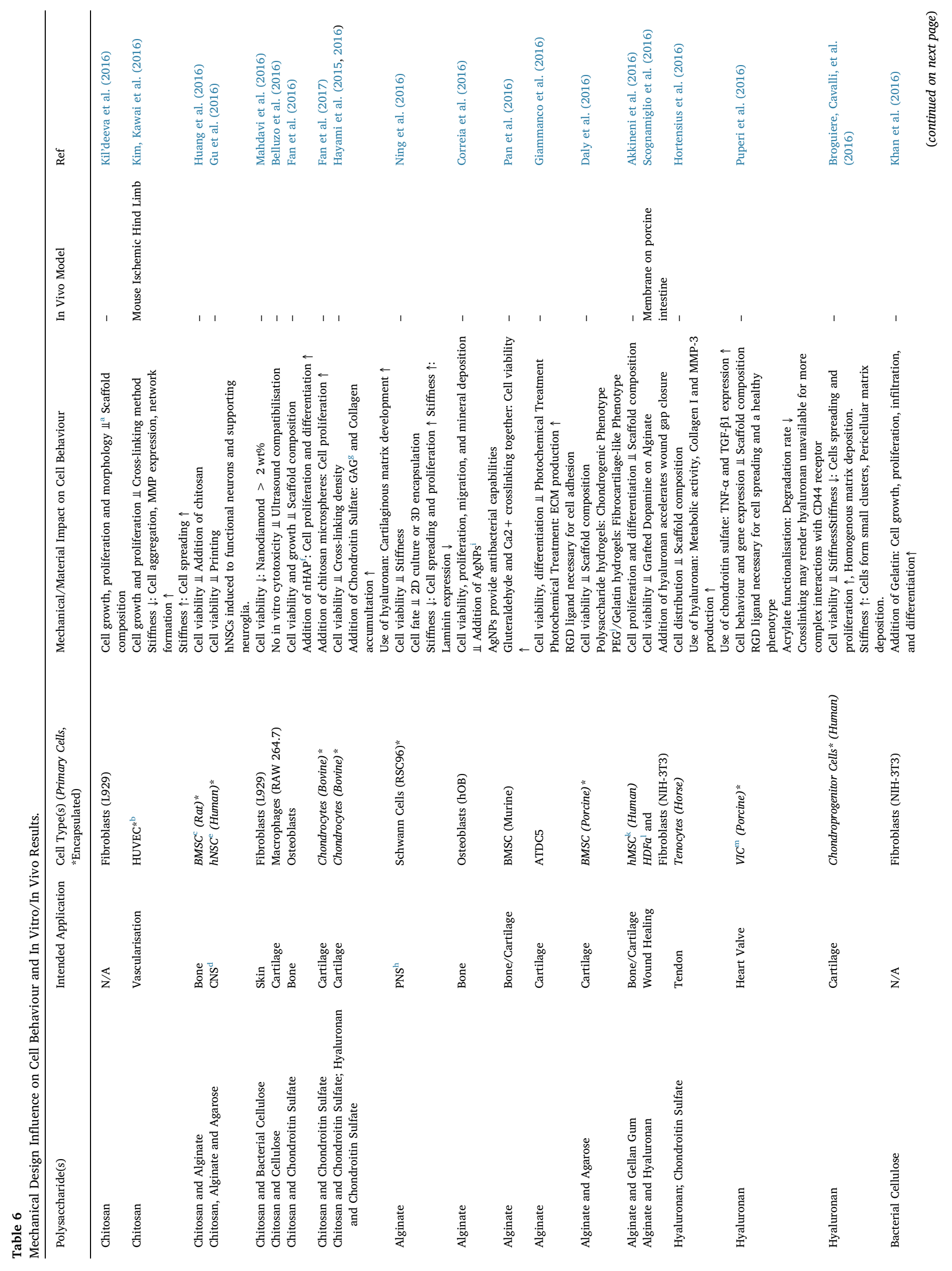


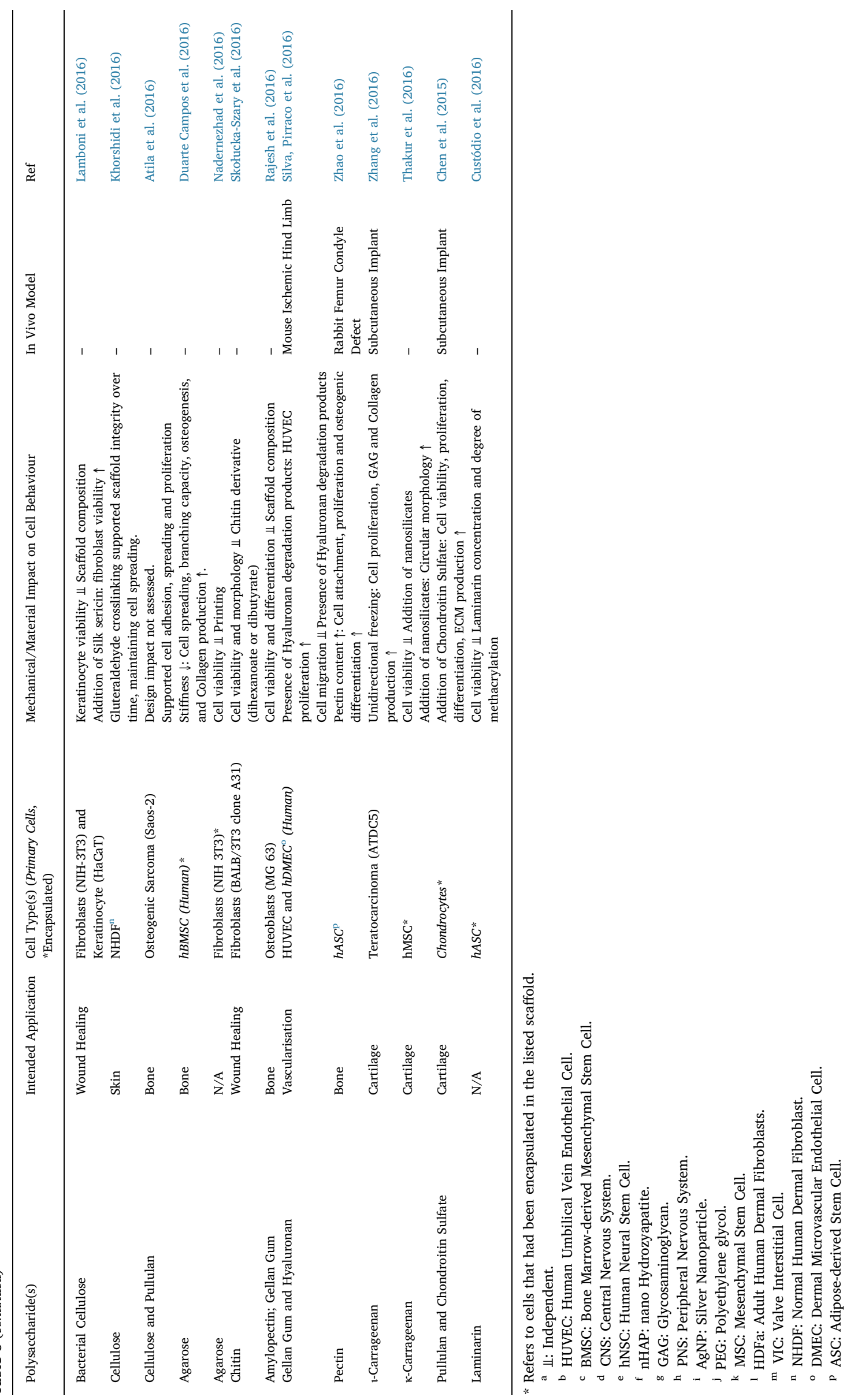


HUVEC (human umbilical vein endothelial cells) encapsulation and stiff bottom layer to support developing microvasculature. Before implantation, the HUVECs encapsulated in the scaffold were cultured for 5 days, allowing the formation of microvascular networks. Over 14 days of implantation, the dual-layer scaffold with microvasculature displayed a significant increase in perfusion compared to both no treatment and an implant of HUVECs encapsulated in a hydrogel, with no significant difference between the latter two. Subjects also showed reduced levels of necrosis in the dual-layer implants. Another study also examined the use of a hydrogel implant in a mouse ischemic hind-limb model, instead using a hydrogel mixture of gellan gum and hyaluronan, taking advantage of the ability for hyaluronic acid degradation products to enhance angiogenesis (Silva, Pirraco et al., 2016). When compared to the no implant control, the hydrogel showed significantly higher development of neovasculature, higher vessel density, and enhanced blood perfusion, but maturation of the developed vasculature was not achieved. A final study of interest using a relevant model was performed by Zhao et al. (2016), wherein pectin was employed to improve the osteogenic activity and compressive strength of a calcium phosphate scaffold, and was evaluated for its bone repairing ability in a rabbit femur condyle cavity defect. The addition of pectin provided the scaffold with improved mechanical properties similar to cancellous bone, while also promoting both improved osteogenic differentiation and formation of new bone when compared to the controls. Though some others investigate the in vivo behaviour of their scaffolds, they primarily assess the presence, if any, of an adverse reaction towards the implant. And while in vivo studies are key for investigating the performance of a scaffold, the model chosen must be appropriate for the intended application. For further information the reader is directed to the following paper and book chapter on the topic (Haier \& Schmidt, 2009; Williams, 2017). Moreover, though many of these studies above observe remarkable results and can conjecture links between certain gross parameters (e.g. stiffness and cell behaviour), a mechanistic understanding of these events remains unclear.

\section{Current limitations}

While significant progress has been made in the production of bioactive tissue engineering scaffolds from polysaccharides, there exist limitations to the currently employed approaches and techniques. These range from factors such as structural reproducibility, vascularisation, and the complexity of the relevant biological environment, to the scope of modifications being applied to polysaccharides and the relevance of the cell studies being performed.

\subsection{Reproducibility of mechanical and structural properties}

Two related and crucial aspects of scaffold design in the pursuit of controlling and directing cell behaviour are the mechanical properties and the architecture of a scaffold, as has become increasingly clear over the years. The surface topography and roughness (Crowder et al., 2016; O'Brien, 2011), material stiffness (Curtis et al., 2006; Engler, Sen, Sweeney, \& Discher, 2006; Hutmacher, 2010; O'Brien, 2011), and features from the microscale down to the nanoscale (Crowder et al., 2016; Curtis et al., 2006; O'Brien, 2011; Stevens \& George, 2005) have all been shown to influence cell behaviour. Additionally, adequate pore size and interconnectivity are necessary to allow cell migration into a scaffold, the diffusion of nutrients into and waste out of a scaffold (O'Brien, 2011), while pore geometry is able to influence the local mechanical stimuli that a cell senses (Campos Marin \& Lacroix, 2015) and is able to influence cell shape and fate (Crowder et al., 2016). Given the importance of these properties, the reproducibility of designed tissue engineering scaffolds becomes a critical component of the actual design process, and is necessary to ensure the repeatability and thus validity of any measurements obtained. This structural reproducibility, however, is still a challenge to achieve, not only with the manufacturing methods commonly used with polymeric systems such as the formation of crosslinked hydrogels, freeze drying, and electrospinning, but even with the more precise additive manufacturing techniques. Local distribution of stresses have been found to vary in polymeric systems (Campos Marin \& Lacroix, 2015) and even in metals, where the geometry and fatigue performance do not precisely match their original design (Ryan, McGarry, Pandit, \& Apatsidis, 2009; Van Bael et al., 2011). In addition to the difficulty in obtaining reproducible scaffold architectures, the rapid formation and establishment of a functional vascular network remains a major limitation.

\subsection{Vascularisation}

In the pursuit of effective and clinically relevant implant solutions, the rapid establishment of functional vasculature is necessary to provide an adequate supply of nutrients and oxygen to the area of implantation. Without a properly vascularized network within an implant, internal regions will become hypoxic, resulting in tissue necrosis. Many limitations to the types of tissue substitutes that may be used exist largely due to the limit of diffusion for oxygen and nutrients that must first be overcome for larger tissues replacements to be viable (Laschke \& Menger, 2016; Rouwkema \& Khademhosseini, 2016). Furthermore, the rate of vascular network formation is limited by the need for the host tissue to first locally degrade the engineered ECM before sprouting, at an average angiogenic vessel growth rate of $5 \mu \mathrm{m} / \mathrm{h}$ (Frueh et al., 2017). To improve this rate, various approaches have been assessed, such as pre-vascularisation strategies (Laschke \& Menger, 2016), along with strategies to obtain more biomimetic materials. Among the latter, aspects such as matrix stiffness and the effects of fluid shear on vessel growth has been tested at varying vessel sizes (Arrigoni et al., 2016; Lesman, Rosenfeld, Landau, \& Levenberg, 2016; Linville, Boland, Covarrubias, Price, \& Tien, 2016), with inconsistent results. Single and multiple pro-angiogenic growth factors have also been studied, finding that the use of a combination of these factors helps support vascularization, resulting in longer network formation and number of branches (Arrigoni et al., 2016), as well as increased vessel formation and maturation when compared to a single growth factor (Rouwkema \& Khademhosseini, 2016). The use of peptides that mimic growth factors has also been shown to be effective, like the agonist peptide QK that replicates the helix region of the vascular endothelial growth factor (VEGF), allowing it to bind to its receptors, inducing angiogenesis and improving vascularisation (Prakash Parthiban, Rana, Jabbari, Benkirane-Jessel, \& Ramalingam, 2017). A more recent pre-vascularisation strategy takes advantage of functional vessel fragments, known as adipose tissue-derived microvascular fragments (ad-MVF), that can be generated in large amounts from fat tissue and have a high vascularisation capacity (Später, Frueh, Menger, \& Laschke, 2017). When seeded onto a scaffold and implanted into a $4 \mathrm{~mm}$ diameter skin defect on mice (Frueh et al., 2017), the ad-MVFs were able to invade into and vascularise throughout the implant, integrating with the host vessels in 14 days. Additionally, the fragments release angiogenic growth factors, contributing to their great potential for recreating a vascular network and connecting to the host vessels. An alternative approach to overcoming the limits for larger tissue implants is to apply a bottom-up assembly of units small enough to remain within the diffusion limit of oxygen and nutrients, such as with cell-encapsulating microgels (Guven et al., 2015), where the substituent units can be built up in a directed or self-assembling manner amongst each other or potentially around a scaffold with predefined channels. Though our understanding is progressing, it is evident that even in this one facet of tissue regeneration there is a level of complexity that is both difficult to decipher and to replicate.

\subsection{Biological complexity and the extracellular matrix}

One major barrier to the advancement of current approaches in 
tissue engineering is the sheer complexity of the biological environment in which these materials are intended to be used. Contributing to this complexity are the diversity of cell types and their spatiotemporal variations of surface receptors (Caré \& Soula, 2012; Shankaran, Resat, \& Wiley, 2007; Sungkaworn, Rieken, Lohse, \& Calebiro, 2014), the immune and foreign body responses (Anderson, Rodriguez, \& Chang, 2008; Morais, Papadimitrakopoulos, \& Burgess, 2010; Sheikh, Brooks, Barzilay, Fine, \& Glogauer, 2015) and the natural processes involved in tissue regeneration and wound healing (Clevers, Loh, \& Nusse, 2014; Coffman, Rieger, Rogers, Updike, \& Yin, 2016; Velnar, Bailey, \& Smrkolj, 2009; Zhao, Tumaneng, \& Guan, 2011). As the considerable extent of this area is not within the scope of this review, focus will be given instead to a brief overview of the composition and functions of the extracellular matrix. Essentially the blueprint for the design of tissue engineering scaffolds, the extracellular matrix is an intricate network surrounding cells that provides many cues directing cell behaviour from migration, adhesion and proliferation, to differentiation and death, while being constantly remodelled as needed in order to regulate this behaviour (Hynes, 2009; Lu, Takai, Weaver, \& Werb, 2011; Schwartz, 2010). These cues are provided via the surface receptors of its many components (Hynes \& Naba, 2012; Lu et al., 2011), the mechanical properties of these components (Schwartz, 2010), as well as by growth factors and other soluble cues sequestered within its network. This network consists of a wide variety of approximately 300 known core components including many proteoglycans, glycosaminoglycans and glycoproteins (Hynes \& Naba, 2012), and is structurally diverse, with collagen alone having 43 subunits. The composition of the ECM is also influenced by multiple factors, varying with the type of tissue (Beachley et al., 2015), within a given tissue (Klaas et al., 2016), with the age or developmental stage (Frantz et al., 2010; Williams, Quinn, Georgakoudi, \& Black, 2014), and whether a tissue is wounded or healthy (Frantz et al., 2010; Quan \& Fisher, 2015). As the architecture and elements of the ECM are many and spatiotemporally diverse, the narrow scope of polysaccharide modifications currently being applied would doubtfully mimic the associated complexity of function of this environment. While the preliminary assessments of cell adhesion and proliferation of an immortal cell line to these materials is essential, it is not sufficient to be indicative of an appropriate design.

\subsection{Limited scope of polysaccharide modifications applied}

A significant limitation in the current use of polysaccharides in tissue engineering studies is the common off-the-shelf application of these materials. Being naturally derived imparts a high degree of variability in the materials being used to construct these scaffolds, not only from the typically mentioned influences such as sourcing, processing, and the potential presence of impurities, but also in the distribution and availability of the bioactive domains present on these molecules. With this in mind, it is not unreasonable to expect that this variability will affect both the properties of the scaffold being produced, as well as the interactions between the scaffold and any cells or biomolecules. In addition to their off-the-shelf use, the scope of the modifications of polysaccharides being applied is narrow, with two predominant approaches, as discussed above. The first is for ease of processing and producing a scaffold, such as the addition of functional groups for crosslinking (e.g. methacrylate for UV crosslinking (Custódio et al., 2016; Reys et al., 2016)) or improving the solubility of the polysaccharide in a chosen solvent (e.g. carboxymethylation of chitosan for water solubility (Fan et al., 2017)). The other is to simply introduce a small set of ECM-mimetic functionalities, such as integrin binding through the addition of fibronectin (Silva, Custódio et al., 2016) or the RGD peptide (Bernstein-Levi et al., 2016), and enzyme-mediated scaffold degradation through the introduction of MMP-cleavable crosslinks (Broguiere, Cavalli, et al., 2016). As previously mentioned, the replication of only a few aspects of the complex extracellular environment, though capable of inducing cell adhesion, proliferation, and the presence lineage markers, is unlikely to be sufficient to properly replace all necessary functions of this environment for the period of time that the scaffolding remains in the body. To address these two limitations, as well as those mentioned above, the rational design of these molecules will be key.

\section{Rational design of polysaccharides}

The rational and precise design of polysaccharides would not only ensure a more uniform product to design scaffolds with, limiting any impacts of structural/functional variability, but would also allow the elucidation of the many molecular mechanisms at play in the interaction between cells or biomolecules and the surfaces constructed from these polysaccharides. To begin to grasp these interactions, the effects of chain orientation and arrangement as well as those of surface groups, their distribution, conformation, and availability will need to be understood. Some cell-surface studies have been performed on polysaccharide surfaces, for instance, where Oliveira et al. examined the effects of layer-by-layer assemblies of the cationic and aminated chitosan, and the anionic sulphated polysaccharides $\kappa$-, 1 -, and $\lambda$-carrageenan (with 1,2 , and 3 sulfate groups per disaccharide, respectively) on osteoblast activity, underlining the impact of surface amine and sulphur content, along with the influence of their conformation and density on cell behaviour (Oliveira et al., 2013). Yet while these studies exist, very few systematic studies have been performed on polysaccharide model surfaces attempting to disentangle the effects of surface groups, mechanical properties, and topography. The majority of studies assessing the effects of surface topography and surface chemistry on cell-surface interactions have been performed on patterned glass, silicon, and gold coated surfaces, as well as on synthetic polymer substrates. Nonetheless, the assessment of various distributions and densities of surface chemistries or monolayers that have been performed on these substrates are useful in guiding towards potential designs of interest.

Many of these cell-surface studies report on the effects of topography (Christo et al., 2016; Curran et al., 2010; Reynolds, Pedersen, Riehle, \& Gadegaard, 2012; Yang, Rose, Gadegaard, \& Alexander, 2009), and various surface chemistries which examine properties such as water contact angles (Arima \& Iwata, 2007; Christo et al., 2016; Ma, Gao, Gong, \& Shen, 2003; Oliveira et al., 2013; Rashidi, Yang, \& Shakesheff, 2014; Yang et al., 2009), surface charge (Arima \& Iwata, 2007; Lee, Ducheyne, Lynch, Boettiger, \& Composto, 2006), and protein adsorption (Pacelli et al., 2016; Rostam et al., 2016), though the end results, expectedly, vary with the cell type being tested, the type of substrate, and the applied surface patterning/functionality being used. There are, however, consistencies that exist between these studies. The mechanism of protein adsorption which generally occurs through hydrophobic interactions is affected by the presence of hydrophilic surface groups. These groups affect the amount of surface water resulting in a lower interfacial free energy with the biological fluids, reducing protein adherence (Lee et al., 2006; Pacelli et al., 2016). Moreover, there have been results identifying water contact angles that are more moderate are preferable for cell adherence and proliferation, though the range of the determined 'ideal' water contact angles is also variable (Arima \& Iwata, 2007; Yang et al., 2009). These results are further convoluted by the difficulty in decoupling and understanding the observed effects of the surface modifications and their potential range of activities, with, for example, varying surface chemistries having been found to effect cell phenotypes (Curran et al., 2010), foreign body response to a material (Rostam et al., 2016), as well as the immune response (Christo et al., 2016). While these studies are useful in identifying general groupings of chemical functionalities in terms of, for example, surface charge, hydrophilicity, and acidic or basic nature, the rationale behind the use of these chemistries is largely arbitrary and further hindered by their slow incremental processes of discovery.

Many groups have sought to tackle the latter issue by generating 
high-throughput arrays involving large libraries of polymers (Anderson, Levenberg, \& Langer, 2004; Hook et al., 2012; Mei et al., 2010; Patel et al., 2015), peptides (Zhang \& Kilian, 2014), ECM components (Flaim, Chien, \& Bhatia, 2005; Flaim, Teng, Chien, \& Bhatia, 2008), and even topographies (Hulsman et al., 2015). These high-throughput screening studies allow the rapid identification of scaffold compositions and properties of interest for a given cell type, for cell differentiation or stemness (2008, Flaim et al., 2005; Kim, Lee et al., 2016), for the bacterial response of a surface (Hook et al., 2012), as well as the adsorbed protein content (Wagner \& Castner, 2001; Yang et al., 2010). This rapid screening of various molecular combinations provides a more concrete starting scaffold composition to improve on and some insight into the mechanisms that could be at play based on the determined compositions of interest, but in many cases the initial design of the sampled libraries have an unclear driving rationale. When it comes to polysaccharides in high-throughput assays, the focus turns not simply to uncovering the nature behind carbohydrate-mediated interactions, but to understanding one of the more encrypted aspects of biology: the glycome.

\subsection{The glycome}

With an astounding degree of diversity and complexity, the glycome refers to the complete collection of carbohydrates, or glycans, in an organism. While the combinatorial possibilities of nucleic acids and amino acids are limited by the number of permutations possible by their phosphodiester and peptide bonds, respectively, the monosaccharides that make up glycans can differ based on their ring size, anomeric configuration, linkage points, and branching (Gupta \& Surolia, 2012; Šebestík, Reiniš, \& Ježek, 2012). Even when limiting this to the 10 common sugar residues found in the human body, a trimer of these permits over $10^{5}$ different structural isomers, more than an order of magnitude greater than the potential trimers using the 20 amino acids (Šebestík et al., 2012; Wang, 2014). As these glycan moieties found covering the surface of the many glycoproteins, glycolipids, and other glycoconjugates are not encoded in the human genome, being instead produced by complex glycosylation events involving enzymes such as glycosidases and glycosyltransferases, their structure and location among these molecules is heterogeneous, complex, and difficult to predict (Russo \& Cipolla, 2016; Varki et al., 2015).

This complexity, combined with the many biological functions of these glycans, including, but not limited to, immune recognition, cell fate, cell adhesion, and molecular trafficking and clearance (Ohtsubo \& Marth, 2006; Varki \& Gagneux, 2015) further emphasizes the need for applications of rationally and precisely designed polysaccharides. Although these results may be difficult to decipher owing to the complexity of the interactions occurring within the physiological environment, the majority of interaction events with glycans occur at their terminal positions, with fewer common core structures (Varki et al., 2015). With the developments in carbohydrate synthesis and of glycan microarrays (Briard, Jiang, Moremen, Macauley, \& Wu, 2018; Park, Gildersleeve, Blixt, \& Shin, 2013; Rillahan \& Paulson, 2011), their functional roles and the impacts of their modifications are slowly being uncovered. And while through systems-level analyses and bioinformatics studies we are improving our understanding of the glycome, the pattering of it may not currently be a realistic target in designing scaffolds. However, the glycome exists as an added layer of complexity over a different collective, known as the matrisome, that can be leveraged for rational scaffold designs.

\subsection{The matrisome}

The matrisome is defined as the ensemble of ca. 1000 identified genes encoding the extracellular matrix proteins and associated factors, and can be divided into two major categories (Naba et al., 2016, Hynes \& Naba, 2012; Naba et al., 2012): the core matrisome, which consists of
ECM proteoglycans, glycoproteins, and collagens; and the matrisomeassociated proteins, which includes all ECM-affiliated proteins, regulators and secreted factors. By taking advantage of these well annotated matrisome lists, coupled with the international effort of several groups and consortiums curating an extensive amount of publicly available experimental data in gene (Brown et al., 2015; Zerbino et al., 2018), protein (Berman, Henrick, Nakamura, \& Markley, 2007; Berman, Henrick, \& Nakamura, 2003; The UniProt Consortium, 2017; Wilhelm et al., 2014), and interaction databases (Orchard et al., 2012; Szklarczyk et al., 2015), our knowledge of the ECM can effectively be queried concerning a given tissue or cell type. The entire matrisome and its subsets have also been categorized into 10 separate gene sets in the Molecular Signatures Database (MSigDB) for ease of analysis (Liberzon et al., 2011; Naba et al., 2016; Subramanian et al., 2005). Considering the overall aim of tissue engineering in mimicking the functionality of the extracellular environment, our understanding of the matrisome and the interactions that occur within and among its members would be a feasible starting point in rationally designing tissue engineering materials. One could imagine the selection of key proteins or other factors based on their known associated interactions and functionality of interest, an assessment of the mechanisms of these interactions, and the translation of this mechanism into biomaterial design. This approach would provide a more meaningful outcome and understanding of the inclusion of specific chemistries and their 3D organisation given their basis in one or more existing biological functions, as opposed to the unpredictable effects of coating, combining or conjugating scaffolds haphazardly with molecules that confer a desirable effect and post-hoc interpreting what it could mean, such as the cell-adhesive nature of the widely applied RGD peptide sequence.

\subsection{Case study: the notorious RGD}

The most prevalently used cell-adhesive peptide motif, the RGD sequence was identified over 30 years ago in fibronectin (Pierschbacher \& Ruoslahti, 1984). This recognition sequence is also present in other cell-adhesive ECM proteins such as vitronectin and fibrinogen. While a cursory search shows it makes up $85 \%$ of the focus using peptide binding motifs in tissue engineering, it only accounts for binding with 8 of the 24 known integrin heterodimers (Kapp et al., 2016; Plow, Haas, Zhang, Loftust, \& Smith, 2000). Moreover, while other integrin recognition sequences such as the YIGSR and IKVAV of laminin, and the DGEA or GFOGER of collagen, among others, are known (Huettner, Dargaville, \& Forget, 2018) and have been known for some time (Yamada, 1991), their application has been largely overshadowed by the use of this single sequence. Aside from the clear drawback that the use of the RGD sequence alone cannot provide the recognition required to create an effective ECM-mimic, it does not necessarily represent the appropriate variation in compositional recognition among different tissues. Furthermore, its typical application overlooks the capability of integrins to distinguish between the different RGD-containing ECM proteins as well as their mechanism of interaction, not to mention the isoforms of the fibronectin protein itself. Using the RGD peptide sequence as an example through the above-mentioned approach, a potential alternative to its application will be discussed and presented.

To begin, take the example of the protein fibronectin, the originally identified host of the minimal RGD sequence, and one of the many available interaction databases, MatrixDB (Chautard, Ballut, ThierryMieg, \& Ricard-Blum, 2009; Chautard, Fatoux-Ardore, Ballut, ThierryMieg, \& Ricard-Blum, 2011), as it focuses specifically on the extracellular matrix. A search for fibronectin on this database returns a total of 477 interaction partners within the ECM (along with links to the appropriate experimental sources), and in addition to information such as expression data, proteomics data, and 3D structure, two lists of annotations known as UniProtKB keywords (The UniProt Consortium, 2017) and GO (gene ontology) terms (Ashburner et al., 2000; The Gene Ontology Consortium, 2017). Both, though independently developed, 
have a similar function in that their hierarchical vocabulary aids in categorising and retrieving entries of proteins or genes/gene products based on their involvement in a biological process, molecular function, as a cellular component or even if their sequence can differ due to posttranslational modifications. Though currently interested in this protein for its cell adhesive capabilities, it should not be neglected that fibronectin is also involved in a myriad of different processes and functions within the ECM, and that its reduction to a tripeptide sequence would abrogate many of these interactions. Nevertheless, already aware that fibronectin binds to integrin and that this mechanism involves the RGD sequence, though the information in these interconnected databases would lead to the same conclusion, the interaction itself can be focused on. And, as a few years have passed since the identification of the sequence, our knowledge of this interaction has grown considerably.

We have known for some time that the spacing and clustering of RGD ligands has a profound impact on cell adhesion and focal adhesion formation (Huang et al., 2009; Koo, Irvine, Mayes, Lauffenburger, \& Griffith, 2002; Maheshwari, Brown, Lauffenburger, Wells, \& Griffith, 2000; Selhuber-Unkel et al., 2010; Selhuber-Unkel, López-García, Kessler, \& Spatz, 2008), with a spacing of less than $70 \mathrm{~nm}$ being required for effective focal contacts on patterned surfaces, further corroborated by cryo-electron tomography studies which find the focal adhesion sites on the cells themselves exhibit a similar degree of spacing (Patla et al., 2010). Additionally, the existence of metal ion-dependent adhesion sites (MIDAS) and their associated conserved DXSXS motifs (where $X$ is any amino acid) in the $\beta$ subunits of integrin, along with their implication in ligand binding that could involve the aspartic acid residue of the RGD sequence, were also identified over 20 years ago (Bergelson \& Hemler, 1995; Gille \& Swerlick, 1996; Gumbiner, 1996; Lee, Rieu, Amin Arnaout, \& Liddington, 1995; Stewart \& Hogg, 1996; Stewart, Thiel, \& Hogg, 1995). Since then, further interrogation of these mechanisms have helped uncover the roles of metal ion coordination in integrin stabilisation and binding, with a central MIDAS site containing an $\mathrm{Mn}^{2+} / \mathrm{Mg}^{2+}$ ion flanked by $\mathrm{Ca}^{2+}$ ions in an adjacent MIDAS (ADMIDAS) site and a ligand-induced metal binding site (LIMBS) (Chen, Salas, \& Springer, 2003; Craig, Gao, Schulten, \& Vogel, 2004; Luo, Carman, \& Springer, 2007; Mould, Barton, Askari, Craig, \& Humphries, 2003; Nagae et al., 2012; Springer, Zhu, \& Xiao, 2008; Xiong et al., 2001, 2002).

While our understanding of the entire process is becoming increasingly detailed, the associated interactions with the RGD ligand are understood to involve a coordination between the carboxyl group of the aspartic acid residue and the MIDAS ion in the $\beta$ subunit, while the guanidium group of the arginine interacts via salt bridges with residues in the $\alpha$ subunit in a manner dependent on each subunit, conferring selectivity for specific ligands (Donald, Kulp, \& DeGrado, 2011). The interaction with the $\alpha 5$ and $\alpha \mathrm{V}$ subunits, for example, both involve a side-on interaction with the carboxylate of an Asp residue, while the $\alpha 5$ also interacts in a head-on manner via the amide group of a glutamine residue (Fig. 4) (Nagae et al., 2012). Furthermore, the separation between the residues (i.e. the conformation of the ligand), as well as the flanking residues of the RGD sequence further contribute to this affinity for specific integrin heterodimers, and can be chosen in a manner to provide the intended selectivity (Kapp et al., 2016). With all this known, it may then not come as a surprise that surfaces coated with various combinations of functional groups such as carboxyls and amines could permit biological activity, while crosslinking that makes use of these same groups, for instance carbodiimide crosslinking, would prevent their participation in the interactions (Bax et al., 2017; Davidenko et al., 2016). Now reduced to essentially the chemical basis of these interactions, rather than tagging the RGD peptide onto a molecule or material, polysaccharides could be rationally designed with the appropriate groups in the necessary geometric orientation to provide the selectivity required for a given integrin heterodimer as elucidated in the above studies. This could then be extended as a general approach to rationally design materials for precise interactions needed for different biological functionalities.

However, this is performed with the knowledge that fibronectin binds to integrin on the cell surface, providing the desired cell adhesive property. In the case that the molecules and interactions involved in a desired property are unknown, one could query using the aforementioned annotations such as GO terms or UniProtKB keywords for the function or biological process of interest (Ashburner et al., 2000; The Gene Ontology Consortium, 2017). Staying with this example, a search for the GO term 'cell adhesion' (GO:0007155) would lead to the child term cell-substrate adhesion (GO:0031589), its child term cell-matrix adhesion (GO:0007160), and so forth. Similarly, a search for the GO term 'extracellular matrix' (GO:0031012) would lead to its respective child terms. Using the two more general GO terms for 'cell adhesion' and 'extracellular matrix' as a query in a protein sequence database such as UniProt (The UniProt Consortium, 2017), along with a filter for the organism of interest, would lead the curious researcher to a list containing entries for many of the familiar integrin binding proteins including collagen, laminin, vitronectin, thrombospondin, and, of course, fibronectin. Upon selecting one of these entries, an extensive aggregate containing or linking to information from the protein's function, sequence, 3D structure, to its pathology, post-translational modifications, and interactions are available for analysis along with all associated publications where relevant. From there, a short literature survey would return the enquiring mind to our starting point in the case study above. Naturally, while this whole approach requires an awareness of the existence of these databases and a certain grasp of the terminology to extract the information of interest, it is at best a simplistic use of these tools, with the full potential requiring more rigorous bioinformatic analyses. Of course, collaborations should be far from the last thing on our minds in such an inherently multidisciplinary field of research. What is hopefully clear is that the currently applied 'mimetic' functionalities included in tissue engineering material design do not even begin to scratch the surface of the breadth and variety of interactions available within the ECM that could be examined in a similar manner to inspire more effective and rationally designed constructs.

\subsection{Topochemical engineering of static and dynamic polysaccharide-based scaffolds}

Topochemical engineering is a method to design fractionation (disassembly) and fabrication (assembly) of highly engineered

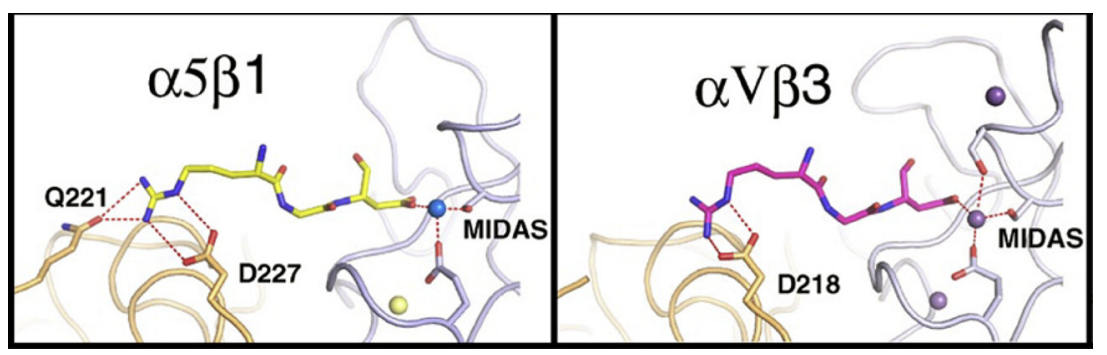

Fig. 4. Binding modes of a linear RGD peptide to the $\alpha 5 \beta 1$ and $\alpha \mathrm{V} \beta 3$ integrins. Carbon, Oxygen, and Nitrogen represented in yellow/magenta, red, and blue, respectively. Figure adapted from (Nagae et al., 2012) (for interpretation of the references to colour in this figure legend, the reader is referred to the web version of this article). 
functional materials using a combination of molecular and supramolecular techniques (Sobhanadhas, Kesavan, \& Fardim, 2018). Multifunctionalisation of polysaccharides with charged or hydrophobic groups allows the directed topochemical assembly of complex nanoarchitectures suitable for the cellular microenvironment. Multifunctionalisation of polysaccharides also allows the introduction of dynamic features to the scaffold through engineering of cell-surface interactions. It is evident that surface chemistry and topography, along with mechanical properties of the substrate material are critical factors in cell-surface interactions and that it is necessary to carry out well designed systematic studies on model surfaces in order to effectively decode these interactions. However, the design of the scaffold itself, and of its constituents, is just as crucial. There must be some rationale behind the selected designs to provide a foundation with which to understand the potential impact of its choice. One approach to this would be to combine topochemical engineering with the wealth of knowledge and data available from extensive bioinformatics studies on the matrisome and the nature of the interactions therein to drive the rational design of materials for scaffolds, even on a tissue-by-tissue basis. This, in combination with studies of the mechanics of cell-surface interactions and the continuing development of instruments and methods for characterising cell interactions in a 3D environment would greatly advance our understanding of how to rationally design appropriate biomimetic materials for tissue engineering. Furthermore, this approach would help reveal if there is a minimal composition within these materials that could adequately mimic the necessary ECM functionality for a given application without the need to completely reproduce all native functionality of this complex environment.

\section{Conclusions}

With the recent progress and increasing interest in the manufacturing of 3D polysaccharide materials for tissue engineering, it is becoming clearer that our control over the structure, and thus function of these materials from the macro- to molecular-scale is hindering their capabilities as suitable and effective scaffolds. As we are without a complete understanding of the molecular mechanisms involved in the interaction between cells and biomolecules in a physiologically relevant environment, and the surfaces with which they are interacting, we lack the core knowledge needed to properly understand how to design materials for use in the context of tissue engineering. Alongside the developments being made in the processes of manufacturing more precise 3D polysaccharide materials for tissue engineering, progress must also be made in our grasp of these fundamental interactions through well characterised studies with model surfaces. The rational and precise design of polysaccharides will be crucial in gaining control over the interactions that these materials have within a cellular context, by ensuring both a more controlled product with which to produce these scaffolds, while also aiding in the elucidation of the molecular mechanisms that are involved in these interactions. Taking advantage of topochemical engineering methods and the considerable structural and functional diversity of polysaccharides through their rational and precise design, and consequently their more effective application in these two areas of tissue engineering scaffold design, will be critical in the progression of the field.

\section{Appendix A. Supplementary data}

Supplementary material related to this article can be found, in the online version, at doi:https://doi.org/10.1016/j.carbpol.2018.10.039.

\section{References}

Akkineni, A., Ahlfeld, T., Funk, A., Waske, A., Lode, A., \& Gelinsky, M. (2016). Highly concentrated alginate-gellan gum composites for 3D plotting of complex tissue engineering scaffolds. Polymers, 8(5), 170. https://doi.org/10.3390/polym8050170.
Amini, A. R., Laurencin, C. T., \& Nukavarapu, S. P. (2012). Bone tissue engineering: Recent advances and challenges. Critical Reviews in Biomedical Engineering, 40(5), 363-408.

Anderson, D. G., Levenberg, S., \& Langer, R. (2004). Nanoliter-scale synthesis of arrayed biomaterials and application to human embryonic stem cells. Nature Biotechnology, 22(7), 863-866. https://doi.org/10.1038/nbt981.

Anderson, J. M., Rodriguez, A., \& Chang, D. T. (2008). Foreign body reaction to biomaterials. Seminars in Immunology, 20(2), 86-100. https://doi.org/10.1016/j.smim. 2007.11.004.

Aria, M., \& Cuccurullo, C. (2017). Bibliometrix: An R-tool for comprehensive science mapping analysis. Journal of Informetrics, 11(4), 959-975. https://doi.org/10.1016/J. JOI.2017.08.007.

Arima, Y., \& Iwata, H. (2007). Effect of wettability and surface functional groups on protein adsorption and cell adhesion using well-defined mixed self-assembled monolayers. Biomaterials, 28(20), 3074-3082. https://doi.org/10.1016/j. biomaterials.2007.03.013.

Arrigoni, C., Bongio, M., Talò, G., Bersini, S., Enomoto, J., Fukuda, J., ... Moretti, M. (2016). Rational design of prevascularized large 3D tissue constructs using computational simulations and biofabrication of geometrically controlled microvessels. Advanced Healthcare Materials, 5(13), 1617-1626. https://doi.org/10.1002/adhm. 201500958.

Ashburner, M., Ball, C. A., Blake, J. A., Botstein, D., Butler, H., Cherry, J. M., ... Sherlock, G. (2000). Gene ontology: Tool for the unification of biology. The Gene Ontology Consortium Nature Genetics, 25(1), 25-29. https://doi.org/10.1038/75556.

Atila, D., Keskin, D., \& Tezcaner, A. (2016). Crosslinked pullulan/cellulose acetate fibrous scaffolds for bone tissue engineering. Materials Science and Engineering C, 69, 1103-1115. https://doi.org/10.1016/j.msec.2016.08.015.

Bax, D. V., Davidenko, N., Gullberg, D., Hamaia, S. W., Farndale, R. W., Best, S. M., ... Cameron, R. E. (2017). Fundamental insight into the effect of carbodiimide crosslinking on cellular recognition of collagen-based scaffolds. Acta Biomaterialia, 49, 218-234. https://doi.org/10.1016/j.actbio.2016.11.059.

Beachley, V. Z., Wolf, M. T., Sadtler, K., Manda, S. S., Jacobs, H., Blatchley, M. R., ... Elisseeff, J. H. (2015). Tissue matrix arrays for high-throughput screening and systems analysis of cell function. Nature Methods, 12(12), 1197-1204. https://doi.org/ 10.1038/nmeth.3619.

Belluzo, M. S., Medina, L. F., Cortizo, A. M., \& Cortizo, M. S. (2016). Ultrasonic compatibilization of polyelectrolyte complex based on polysaccharides for biomedical applications. Ultrasonics Sonochemistry, 30, 1-8. https://doi.org/10.1016/j.ultsonch. 2015.11.022.

Bergelson, J. M., \& Hemler, M. E. (1995). Integrin-ligand binding. Do integrins use a "MIDAS touch" to grasp an Asp? Current Biology: CB, 5(6), 615-617. https://doi.org/ 10.1016/S0960-9822(95)00124-2.

Berman, H., Henrick, K., \& Nakamura, H. (2003). Announcing the worldwide protein data bank. Nature Structural \& Molecular Biology, 10(12), 980. https://doi.org/10.1038/ nsb1203-980.

Berman, H., Henrick, K., Nakamura, H., \& Markley, J. L. (2007). The worldwide Protein Data Bank (wwPDB): Ensuring a single, uniform archive of PDB data. Nucleic Acids Research, 35(Database), D301-D303. https://doi.org/10.1093/nar/gk1971.

Bernstein-Levi, O., Ochbaum, G., \& Bitton, R. (2016). The effect of covalently linked RGD peptide on the conformation of polysaccharides in aqueous solutions. Colloids and Surfaces B, Biointerfaces, 137, 214-220. https://doi.org/10.1016/j.colsurfb.2015.06. 042.

Bian, S., He, M., Sui, J., Cai, H., Sun, Y., Liang, J., ... Zhang, X. (2016). The self-crosslinking smart hyaluronic acid hydrogels as injectable three-dimensional scaffolds for cells culture. Colloids and Surfaces B, Biointerfaces, 140, 392-402. https://doi.org/10. 1016/j.colsurfb.2016.01.008.

Bierhalz, A. C. K., \& Moraes, A. M. (2016). Tuning the properties of alginate-chitosan membranes by varying the viscosity and the proportions of polymers. Journal of Applied Polymer Science, 133(46), https://doi.org/10.1002/app.44216.

Bonilla, M. R., Lopez-Sanchez, P., Gidley, M. J., \& Stokes, J. R. (2016). Micromechanical model of biphasic biomaterials with internal adhesion: Application to nanocellulose hydrogel composites. Acta Biomaterialia, 29, 149-160. https://doi.org/10.1016/j. actbio.2015.10.032.

Briard, J. G., Jiang, H., Moremen, K. W., Macauley, M. S., \& Wu, P. (2018). Cell-based glycan arrays for probing glycan-glycan binding protein interactions. Nature Communications, 9(1), 880. https://doi.org/10.1038/s41467-018-03245-5.

Broguiere, N., Cavalli, E., Salzmann, G. M., Applegate, L. A., \& Zenobi-Wong, M. (2016). Factor XIII cross-linked hyaluronan hydrogels for cartilage tissue engineering. ACS Biomaterials Science \& Engineering, 2(12), 2176-2184. https://doi.org/10.1021/ acsbiomaterials.6b00378.

Broguiere, N., Isenmann, L., \& Zenobi-Wong, M. (2016). Novel enzymatically cross-linked hyaluronan hydrogels support the formation of 3D neuronal networks. Biomaterials, 99, 47-55. https://doi.org/10.1016/j.biomaterials.2016.04.036.

Brown, G. R., Hem, V., Katz, K. S., Ovetsky, M., Wallin, C., Ermolaeva, O., ... Murphy, T. D. (2015). Gene: A gene-centered information resource at NCBI. Nucleic Acids Research, 43(Database issue), D36-42. https://doi.org/10.1093/nar/gku1055.

Butcher, D. T., Alliston, T., \& Weaver, V. M. (2009). A tense situation: Forcing tumour progression. Nature Reviews Cancer, 9(2), 108-122. https://doi.org/10.1038/ nrc2544.

Campos Marin, A., \& Lacroix, D. (2015). The inter-sample structural variability of regular tissue-engineered scaffolds significantly affects the micromechanical local cell environment. Interface Focus, 5(2).

Cardoso, M. J., Costa, R. R., \& Mano, J. F. (2016). Marine origin polysaccharides in drug delivery systems. Marine Drugs, 14(2), https://doi.org/10.3390/md14020034.

Caré, B. R., \& Soula, H. A. (2012). The effect of membrane receptor clustering on spatiotemporal cell signalling dynamics. Berlin, Heidelberg: Springer50-61. https://doi.org/ 
10.1007/978-3-642-28792-3_8

Celik, E., Bayram, C., Akçapınar, R., Türk, M., \& Denkbas, E. B. (2016). The effect of calcium chloride concentration on alginate/Fmoc-diphenylalanine hydrogel networks. Materials Science and Engineering C, 66, 221-229. https://doi.org/10.1016/j. msec.2016.04.084.

Chautard, E., Ballut, L., Thierry-Mieg, N., \& Ricard-Blum, S. (2009). MatrixDB, a database focused on extracellular protein-protein and protein-carbohydrate interactions. Bioinformatics (Oxford, England), 25(5), 690-691. https://doi.org/10.1093/ bioinformatics/btp025.

Chautard, E., Fatoux-Ardore, M., Ballut, L., Thierry-Mieg, N., \& Ricard-Blum, S. (2011) MatrixDB, the extracellular matrix interaction database. Nucleic Acids Research, 39(Database), D235-D240. https://doi.org/10.1093/nar/gkq830.

Chen, F., Yu, S., Liu, B., Ni, Y., Yu, C., Su, Y., ... Yan, D. (2015). An injectable enzymatically crosslinked carboxymethylated pullulan/chondroitin sulfate hydrogel for cartilage tissue engineering. Nature Publishing Grouphttps://doi.org/10.1038/srep20014.

Chen, J., Salas, A., \& Springer, T. A. (2003). Bistable regulation of integrin adhesiveness by a bipolar metal ion cluster. Nature Structural \& Molecular Biology, 10(12), 995-1001. https://doi.org/10.1038/nsb1011.

Christo, S. N., Bachhuka, A., Diener, K. R., Mierczynska, A., Hayball, J. D., \& Vasilev, K. (2016). The role of surface nanotopography and chemistry on primary neutrophil and macrophage cellular responses. Advanced Healthcare Materials, 5(8), 956-965. https://doi.org/10.1002/adhm.201500845.

Clevers, H., Loh, K. M., \& Nusse, R. (2014). An integral program for tissue renewal and regeneration: Wnt signaling and stem cell control. Science, 346(6205), 1248012. https://doi.org/10.1126/science.1248012.

Coffman, J. A., Rieger, S., Rogers, A. N., Updike, D. L., \& Yin, V. P. (2016). Comparative biology of tissue repair, regeneration and aging. NPJ Regenerative Medicine, 1(November), 16003. https://doi.org/10.1038/npjregenmed.2016.3.

Correia, T. R., Figueira, D. R., de Sá, K. D., Miguel, S. P., Fradique, R. G., Mendonça, A. G., ... Correia, I. J. (2016). 3D Printed scaffolds with bactericidal activity aimed for bone tissue regeneration. International Journal of Biological Macromolecules, 93(Pt. B), 1432-1445. https://doi.org/10.1016/j.ijbiomac.2016.06.004.

Craig, D., Gao, M., Schulten, K., \& Vogel, V. (2004). Structural insights into how the MIDAS ion stabilizes integrin binding to an RGD peptide under force. Structure, 12(11), 2049-2058. https://doi.org/10.1016/j.str.2004.09.009.

Crowder, S. W., Leonardo, V., Whittaker, T., Papathanasiou, P., \& Stevens, M. M. (2016). Material cues as potent regulators of epigenetics and stem cell function. Cell Stem Cell, 18(1), 39-52. https://doi.org/10.1016/j.stem.2015.12.012.

Curran, J. M., Stokes, R., Irvine, E., Graham, D., Amro, N. A., Sanedrin, R. G., ... Moller, M. (2010). Introducing dip pen nanolithography as a tool for controlling stem cell behaviour: Unlocking the potential of the next generation of smart materials in regenerative medicine. Lab on A Chip, 10(13), 1662-1670. https://doi.org/10.1039/ C004149A.

Curtis, A. S. G., Dalby, M., \& Gadegaard, N. (2006). Cell signaling arising from nanotopography: Implications for nanomedical devices. Nanomedicine (London, England), 1(1), 67-72. https://doi.org/10.2217/17435889.1.1.67.

Custódio, C. A., Reis, R. L., \& Mano, J. F. (2016). Photo-cross-linked laminarin-based hydrogels for biomedical applications. Biomacromolecules, 17(5), 1602-1609. https:// doi.org/10.1021/acs.biomac.5b01736.

Daly, A. C., Critchley, S. E., Rencsok, E. M., \& Kelly, D. J. (2016). A comparison of different bioinks for 3D bioprinting of fibrocartilage and hyaline cartilage. Biofabrication, 8(4), 045002. https://doi.org/10.1088/1758-5090/8/4/045002.

Davidenko, N., Schuster, C. F., Bax, D. V., Farndale, R. W., Hamaia, S., Best, S. M., Cameron, R. E. (2016). Evaluation of cell binding to collagen and gelatin: A study of the effect of 2D and 3D architecture and surface chemistry. Journal of Materials Science Materials in Medicine, 27(10), 148. https://doi.org/10.1007/s10856-016 5763-9.

Donald, J. E., Kulp, D. W., \& DeGrado, W. F. (2011). Salt bridges: Geometrically specific, designable interactions. Proteins Structure Function and Bioinformatics, 79(3), 898-915. https://doi.org/10.1002/prot.22927.

Dong, D., Hao, T., Wang, C., Zhang, Y., Qin, Z., Yang, B., ... Li, J. (2018). Zwitterionic starch-based hydrogel for the expansion and "stemness" maintenance of brown adipose derived stem cells. Biomaterials, 157, 149-160. https://doi.org/10.1016/J. BIOMATERIALS.2017.12.011.

Duarte Campos, D. F., Blaeser, A., Buellesbach, K., Sen, K. S., Xun, W., Tillmann, W., .. Fischer, H. (2016). Bioprinting organotypic hydrogels with improved mesenchymal stem cell remodeling and mineralization properties for bone tissue engineering. Advanced Healthcare Materials, 5(11), 1336-1345. https://doi.org/10.1002/adhm. 201501033.

Dwek, R. A. (1996). Glycobiology: Toward understanding the function of sugars. Chemical Reviews, 96(2), 683-720. https://doi.org/10.1021/cr940283b.

Engler, A. J., Sen, S., Sweeney, H. L., \& Discher, D. E. (2006). Matrix elasticity directs stem cell lineage specification. Cell, 126(4), 677-689. https://doi.org/10.1016/j.cell. 2006.06.044.

Erginer, M., Akcay, A., Coskunkan, B., Morova, T., Rende, D., Bucak, S., ... Toksoy Oner, E. (2016). Sulfated levan from Halomonas smyrnensis as a bioactive, heparin-mimetic glycan for cardiac tissue engineering applications. Carbohydrate Polymers, 149, 289-296. https://doi.org/10.1016/j.carbpol.2016.04.092.

Fan, M., Ma, Y., Tan, H., Jia, Y., Zou, S., Guo, S., ... Hu, X. (2017). Covalent and injectable chitosan-chondroitin sulfate hydrogels embedded with chitosan microspheres for drug delivery and tissue engineering. Materials Science and Engineering C, 71, 67-74. https://doi.org/10.1016/j.msec.2016.09.068.

Fan, T., Chen, J., Pan, P., Zhang, Y., Hu, Y., Liu, X., ... Zhang, Q. (2016). Bioinspired double polysaccharides-based nanohybrid scaffold for bone tissue engineering. Colloids and Surfaces B, Biointerfaces, 147, 217-223. https://doi.org/10.1016/j colsurfb.2016.08.006.
Flaim, C. J., Chien, S., \& Bhatia, S. N. (2005). An extracellular matrix microarray for probing cellular differentiation. Nature Methods, 2(2), 119-125. https://doi.org/10. 1038/nmeth736.

Flaim, C. J., Teng, D., Chien, S., \& Bhatia, S. N. (2008). Combinatorial signaling microenvironments for studying stem cell fate. Stem Cells and Development, 17(1), 29-40. https://doi.org/10.1089/scd.2007.0085.

Frantz, C., Stewart, K. M., \& Weaver, V. M. (2010). The extracellular matrix at a glance. Journal of Cell Science, 123(24).

Frueh, F. S., Später, T., Lindenblatt, N., Calcagni, M., Giovanoli, P., Scheuer, C., ... Laschke, M. W. (2017). Adipose tissue-derived microvascular fragments improve vascularization, Lymphangiogenesis, and integration of dermal skin substitutes. The Journal of Investigative Dermatology, 137(1), 217-227. https://doi.org/10.1016/j.jid. 2016.08.010.

Giammanco, G. E., Carrion, B., Coleman, R. M., \& Ostrowski, A. D. (2016) Photoresponsive polysaccharide-based hydrogels with tunable mechanical properties for cartilage tissue engineering. ACS Applied Materials \& Interfaces, 8(23), 14423-14429. https://doi.org/10.1021/acsami.6b03834.

Gille, J., \& Swerlick, R. A. (1996). Integrins: Role in cell adhesion and communication. Annals of the New York Academy of Sciences, 797(1 Microbial Pat), 93-106. https:// doi.org/10.1111/j.1749-6632.1996.tb52952.x.

Gu, Q., Tomaskovic-Crook, E., Lozano, R., Chen, Y., Kapsa, R. M., Zhou, Q., ... Crook, J. M. (2016). Functional 3D neural mini-tissues from printed gel-based bioink and human neural stem cells. Advanced Healthcare Materials, 5(12), 1429-1438. https:// doi.org/10.1002/adhm.201600095.

Gumbiner, B. M. (1996). Cell adhesion: Review the molecular basis of tissue architecture and morphogenesis. Cell, 84, 345-357. https://doi.org/10.1016/S0092-8674(00) 81279-9.

Gupta, G., \& Surolia, A. (2012). Glycomics: An overview of the complex glycocode. New York, NY: Springer1-13. https://doi.org/10.1007/978-1-4614-3381-1_1.

Guven, S., Chen, P., Inci, F., Tasoglu, S., Erkmen, B., \& Demirci, U. (2015). Multiscale assembly for tissue engineering and regenerative medicine. Trends in Biotechnology, 33(5), 269-279. https://doi.org/10.1016/j.tibtech.2015.02.003.

Haier, J., \& Schmidt, F. (2009). In vivo animal models in tissue engineering. Fundamentals of tissue engineering and regenerative medicine. Berlin, Heidelberg: Springer Berlin Heidelberg773-779. https://doi.org/10.1007/978-3-540-77755-7_53.

Hayami, J. W. S., Waldman, S. D., \& Amsden, B. G. (2015). Photo-cross-linked methacrylated polysaccharide solution blends with high chondrocyte viability, minimal swelling, and moduli similar to load bearing soft tissues. European Polymer Journal, 72, 687-697. https://doi.org/10.1016/j.eurpolymj.2015.01.038.

Hayami, J. W. S., Waldman, S. D., \& Amsden, B. G. (2016). Chondrocyte generation of cartilage-like tissue following photoencapsulation in methacrylated polysaccharide solution blends. Macromolecular Bioscience, 16(7), 1083-1095. https://doi.org/10. 1002/mabi.201500465.

Hemamalini, T., \& Giri Dev, V. R. (2018). Comprehensive review on electrospinning of starch polymer for biomedical applications. International Journal of Biological Macromolecules, 106, 712-718. https://doi.org/10.1016/J.IJBIOMAC.2017.08.079.

Heo, E. Y., Ko, N. R., Bae, M. S., Lee, S. J., Choi, B.-J., Kim, J. H., ... Kwon, I. K. (2017) Novel 3D printed alginate-BFP1 hybrid scaffolds for enhanced bone regeneration. Journal of Industrial and Engineering Chemistry, 45, 61-67. https://doi.org/10.1016/j. jiec.2016.09.003.

Hook, A. L., Chang, C. Y., Yang, J., Luckett, J., Cockayne, A., Atkinson, S., ... Alexander, M. R. (2012). Combinatorial discovery of polymers resistant to bacterial attachment Nature Biotechnology, 30(9), 868-875. https://doi.org/10.1038/nbt.2316.

Hortensius, R. A., Ebens, J. H., \& Harley, B. A. C. (2016). Immunomodulatory effects of amniotic membrane matrix incorporated into collagen scaffolds. Journal of Biomedical Materials Research Part A, 104(6), 1332-1342. https://doi.org/10.1002/jbm.a.35663.

Huang, J., Fu, H., Wang, Z., Meng, Q., Liu, S., Wang, H., ... Dai, J. W. (2016). BMSCsladen gelatin/sodium alginate/carboxymethyl chitosan hydrogel for 3D bioprinting RSC Advances, 6(110), 108423-108430. https://doi.org/10.1039/C6RA24231F.

Huang, J., Gräter, S. V., Corbellini, F., Rinck, S., Bock, E., Kemkemer, R., ... Spatz, J. P. (2009). Impact of order and disorder in RGD nanopatterns on cell adhesion. Nano Letters, 9(3), 1111-1116. https://doi.org/10.1021/nl803548b.

Huettner, N., Dargaville, T. R., \& Forget, A. (2018). Discovering cell-adhesion peptides in tissue engineering: Beyond RGD. Trends in Biotechnology, 36(4), 372-383. https://doi. org/10.1016/j.tibtech.2018.01.008.

Hulsman, M., Hulshof, F., Unadkat, H., Papenburg, B. J., Stamatialis, D. F. Truckenmüller, R., ... Reinders, M. J. T. (2015). Analysis of high-throughput screening reveals the effect of surface topographies on cellular morphology. Acta Biomaterialia, 15, 29-38. https://doi.org/10.1016/j.actbio.2014.12.019.

Hutmacher, D. W. (2010). Biomaterials offer cancer research the third dimension. Nature Materials, 9, 90-93. https://doi.org/10.1038/nmat2619.

Hynes, R. O. (2009). The extracellular matrix: Not just pretty fibrils. Science, 326(5957), 1216-1219. https://doi.org/10.1126/science.1176009.

Hynes, R. O., \& Naba, A. (2012). Overview of the matrisome-An inventory of extracellular matrix constituents and functions. Cold Spring Harbor Perspectives in Biology, 4(1), https://doi.org/10.1101/cshperspect.a004903.

Jha, A. K., Tharp, K. M., Browne, S., Ye, J., Stahl, A., Yeghiazarians, Y., ... Healy, K. E. (2016). Matrix metalloproteinase-13 mediated degradation of hyaluronic acid-based matrices orchestrates stem cell engraftment through vascular integration. Biomaterials, 89, 136-147. https://doi.org/10.1016/j.biomaterials.2016.02.023.

Johnson, J. L., Jones, M. B., Ryan, S. O., \& Cobb, B. A. (2013). The regulatory power of glycans and their binding partners in immunity. Trends in Immunology, 34(6), 290-298. https://doi.org/10.1016/j.it.2013.01.006.

Kapp, T. G., Rechenmacher, F., Neubauer, S., Maltsev, O. V., Cavalcanti-Adam, E. A., Zarka, R., ... Kessler, H. (2016). A comprehensive evaluation of the activity and selectivity profile of ligands for RGD-binding integrins. Nature Publishing Grouphttps://doi.org/ 
10.1038/srep39805

Khan, S., Ul-Islam, M., Ikram, M., Ullah, M. W., Israr, M., Subhan, F., ... Park, J. K. (2016). Three-dimensionally microporous and highly biocompatible bacterial cellulose-gelatin composite scaffolds for tissue engineering applications. RSC Advances, 6(112), 110840-110849. https://doi.org/10.1039/C6RA18847H.

Khorshidi, S., Solouk, A., Karkhaneh, A., Mirzadeh, H., Sharifi, S., \& Mazinani, S. (2016). Effect of crosslinking procedure on structural, thermal, and functional performances of cellulosic nanofibers: A comparison between chemical and photochemical crosslinking. Journal of Applied Polymer Science, 133(34), https://doi.org/10.1002/app. 43832 .

Kil'deeva, N. R., Kasatkina, M. A., Drozdova, M. G., Demina, T. S., Uspenskii, S. A., Mikhailov, S. N., ... Markvicheva, E. A. (2016). Biodegradable scaffolds based on chitosan: Preparation, properties, and use for the cultivation of animal cells. Applied Biochemistry and Microbiology, 52(5), 515-524. https://doi.org/10.1134/ S0003683816050094.

Kim, H. D., Lee, E. A., Choi, Y. H., An, Y. H., Koh, R. H., Kim, S. L., ... Hwang, N. S. (2016). High throughput approaches for controlled stem cell differentiation. Acta Biomaterialia, 34, 21-29. https://doi.org/10.1016/j.actbio.2016.02.022.

Kim, S., Kawai, T., Wang, D., \& Yang, Y. (2016). Engineering a dual-layer chitosan-Lactide hydrogel to create endothelial cell aggregate-induced microvascular networks in vitro and increase blood perfusion in vivo. ACS Applied Materials \& Interfaces, 8(30), 19245-19255. https://doi.org/10.1021/acsami.6b04431.

Klaas, M., Kangur, T., Viil, J., Mäemets-Allas, K., Minajeva, A., Vadi, K., ... Jaks, V. (2016). The alterations in the extracellular matrix composition guide the repair of damaged liver tissue. Scientific Reports, 6(1), 27398. https://doi.org/10.1038/ srep27398.

Koo, L. Y., Irvine, D. J., Mayes, A. M., Lauffenburger, D. A., \& Griffith, L. G. (2002). Coregulation of cell adhesion by nanoscale RGD organization and mechanical stimulus. Journal of Cell Science, 115(Pt 7), 1423-1433.

Kuzmenko, V., Karabulut, E., Pernevik, E., Enoksson, P., \& Gatenholm, P. (2018). Tailormade conductive inks from cellulose nanofibrils for 3D printing of neural guidelines. Carbohydrate Polymers, 189, 22-30. https://doi.org/10.1016/J.CARBPOL.2018.01. 097.

Lamboni, L., Li, Y., Liu, J., \& Yang, G. (2016). Silk sericin-functionalized bacterial cellulose as a potential wound-healing biomaterial. Biomacromolecules, 17(9), 3076-3084. https://doi.org/10.1021/acs.biomac.6b00995.

Laschke, M. W., \& Menger, M. D. (2016). Prevascularization in tissue engineering: Current concepts and future directions. Biotechnology Advances, 34(2), 112-121. https://doi. org/10.1016/j.biotechadv.2015.12.004.

Lee, J.-O., Rieu, P., Amin Arnaout, M., \& Liddington, R. (1995). Crystal structure of the a domain from the a subunit of integrin CR3 (CD11b/CD18). Cell, 80, 631-638. https://doi.org/10.1016/0092-8674(95)90517-0.

Lee, K. Y., \& Mooney, D. J. (2011). Alginate: Properties and biomedical applications. Progress in Polymer Science, 37, 106-126. https://doi.org/10.1016/j.progpolymsci. 2011.06.003.

Lee, M. H., Ducheyne, P., Lynch, L., Boettiger, D., \& Composto, R. J. (2006). Effect of biomaterial surface properties on fibronectin- $\alpha 5 \beta 1$ integrin interaction and cellular attachment. Biomaterials, 27(9), 1907-1916. https://doi.org/10.1016/j.biomaterials. 2005.11.003.

Lee, M., Kim, Y., Ryu, J. H., Kim, K., Han, Y.-M., \& Lee, H. (2016). Long-term, feeder-free maintenance of human embryonic stem cells by mussel-inspired adhesive heparin and collagen type I. Acta Biomaterialia, 32, 138-148. https://doi.org/10.1016/j. actbio.2016.01.008.

Lesman, A., Rosenfeld, D., Landau, S., \& Levenberg, S. (2016). Mechanical regulation of vascular network formation in engineered matrices. Advanced Drug Delivery Reviews, 96, 176-182. https://doi.org/10.1016/j.addr.2015.07.005.

Liberzon, A., Subramanian, A., Pinchback, R., Thorvaldsdottir, H., Tamayo, P., \& Mesirov, J. P. (2011). Molecular signatures database (MSigDB) 3.0. Bioinformatics, 27(12), 1739-1740. https://doi.org/10.1093/bioinformatics/btr260.

Linville, R. M., Boland, N. F., Covarrubias, G., Price, G. M., \& Tien, J. (2016). Physical and chemical signals that promote vascularization of capillary-scale channels. Cellular and Molecular Bioengineering, 9(1), 73-84. https://doi.org/10.1007/s12195-016-0429-8.

Liu, G., Gu, Z., Hong, Y., Cheng, L., \& Li, C. (2017). Electrospun starch nanofibers: Recent advances, challenges, and strategies for potential pharmaceutical applications. Journal of Controlled Release, 252, 95-107. https://doi.org/10.1016/J.JCONREL. 2017.03.016.

Lodhi, G., Kim, Y.-S., Hwang, J.-W., Kim, S.-K., Jeon, Y.-J., Je, J.-Y., ... Park, P.-J. (2014). Chitooligosaccharide and its derivatives: Preparation and biological applications. BioMed Research International, 2014, 654913. https://doi.org/10.1155/2014/ 654913.

Loh, Q. L., \& Choong, C. (2013). Three-dimensional scaffolds for tissue engineering applications: Role of porosity and pore size. Tissue Engineering Part B, Reviews, 19(6), 485-502. https://doi.org/10.1089/ten.teb.2012.0437.

Lu, P., Takai, K., Weaver, V. M., \& Werb, Z. (2011). Extracellular Matrix degradation and remodeling in development and disease. Cold Spring Harbor Perspectives in Biology, 3(12), https://doi.org/10.1101/cshperspect.a005058.

Luo, B.-H., Carman, C. V., \& Springer, T. A. (2007). Structural basis of integrin regulation and signaling. Annual Review of Immunology, 25, 619-647. https://doi.org/10.1146/ annurev.immunol.25.022106.141618.

Ma, Z., Gao, C., Gong, Y., \& Shen, J. (2003). Chondrocyte behaviors on poly-l-lactic acid (PLLA) membranes containing hydroxyl, amide or carboxyl groups. Biomaterials, 24(21), 3725-3730. https://doi.org/10.1016/S0142-9612(03)00247-3.

Mahdavi, M., Mahmoudi, N., Rezaie Anaran, F., \& Simchi, A. (2016). Electrospinning of nanodiamond-modified polysaccharide nanofibers with physico-mechanical properties close to natural skins. Marine Drugs, 14(7), 128. https://doi.org/10.3390/ md14070128.
Maheshwari, G., Brown, G., Lauffenburger, D. A., Wells, A., \& Griffith, L. G. (2000). Cell adhesion and motility depend on nanoscale RGD clustering. Journal of Cell Science, 113(Pt. 1), 1677-1686.

Marth, J. D., \& Grewal, P. K. (2008). Mammalian glycosylation in immunity. Nature Reviews Immunology, 8(11), 874-887. https://doi.org/10.1038/nri2417.

Martínez-Calderon, M., Manso-Silván, M., Rodríguez, A., Gómez-Aranzadi, M., GarcíaRuiz, J. P., Olaizola, S. M., ... Martín-Palma, R. J. (2016). Surface micro- and nanotexturing of stainless steel by femtosecond laser for the control of cell migration. Nature Publishing Grouphttps://doi.org/10.1038/srep36296.

Mei, Y., Saha, K., Bogatyrev, S. R., Yang, J., Hook, A. L., Kalcioglu, Z. I., ... Anderson, D. G. (2010). Combinatorial development of biomaterials for clonal growth of human pluripotent stem cells. Nature Materials, 9(9), 768-778. https://doi.org/10.1038/ nmat2812.

Meimoun, J., Wiatz, V., Saint-Loup, R., Parcq, J., Favrelle, A., Bonnet, F., ... Zinck, P. (2017). Modification of starch by graft copolymerization. Starch - Stärke, 70(1-2), 1600351. https://doi.org/10.1002/star.201600351.

Mero, A., \& Campisi, M. (2014). Hyaluronic acid bioconjugates for the delivery of bioactive molecules. Polymers, 6(2), 346-369. https://doi.org/10.3390/ polym6020346.

Miculescu, F., Maidaniuc, A., Voicu, S. I., Thakur, V. K., Stan, G. E., \& Ciocan, L. T. (2017). Progress in hydroxyapatite-Starch based sustainable biomaterials for biomedical bone substitution applications. ACS Sustainable Chemistry \& Engineering, 5(10), 8491-8512. https://doi.org/10.1021/acssuschemeng.7b02314.

Morais, J. M., Papadimitrakopoulos, F., \& Burgess, D. J. (2010). Biomaterials/tissue interactions: Possible solutions to overcome foreign body response. The AAPS Journal, 12(2), 188-196. https://doi.org/10.1208/s12248-010-9175-3.

Mould, A. P., Barton, S. J., Askari, J. A., Craig, S. E., \& Humphries, M. J. (2003). Role of ADMIDAS cation-binding site in ligand recognition by integrin $\alpha 5 \beta 1$. The Journal of Biological Chemistry, 278(51), 51622-51629. https://doi.org/10.1074/jbc. M306655200.

Muzzarelli, R. A. A., Greco, F., Busilacchi, A., Sollazzo, V., \& Gigante, A. (2012). Chitosan, hyaluronan and chondroitin sulfate in tissue engineering for cartilage regeneration: A review. Carbohydrate Polymers, 89(3), 723-739. https://doi.org/10.1016/j.carbpol. 2012.04.057 Elsevier.

Naba, A., Clauser, K. R., Ding, H., Whittaker, C. A., Carr, S. A., \& Hynes, R. O. (2016). The extracellular matrix: Tools and insights for the "omics" era. Matrix Biology, 49, 10-24 https://doi.org/10.1016/j.matbio.2015.06.003.

Naba, A., Clauser, K. R., Hoersch, S., Liu, H., Carr, S. A., \& Hynes, R. O. (2012). The matrisome: In silico definition and in vivo characterization by proteomics of normal and tumor extracellular matrices. Molecular \& Cellular Proteomics: MCP, 11(4), https://doi.org/10.1074/mcp.M111.014647.

Nadernezhad, A., Khani, N., Skvortsov, G. A., Toprakhisar, B., Bakirci, E., Menceloglu, Y., ... Koc, B. (2016). Multifunctional 3D printing of heterogeneous hydrogel structures. Nature Publishing Grouphttps://doi.org/10.1038/srep33178.

Nagae, M., Re, S., Mihara, E., Nogi, T., Sugita, Y., \& Takagi, J. (2012). Crystal structure of $\alpha 5 \beta 1$ integrin ectodomain: Atomic details of the fibronectin receptor. The Journal of Cell Biology, 197(1), 131-140. https://doi.org/10.1083/jcb.201111077.

Ng, W. L., Yeong, W. Y., \& Naing, M. W. (2016). Development of polyelectrolyte chitosangelatin hydrogels for skin bioprinting. Procedia CIRP, 49, 105-112. https://doi.org/ 10.1016/j.procir.2015.09.002.

Nilsen-Nygaard, J., Strand, S., Vårum, K., Draget, K., \& Nordgård, C. (2015). Chitosan Gels and interfacial properties. Polymers, 7(3), 552-579. https://doi.org/10.3390/ polym7030552.

Ning, L., Xu, Y., Chen, X., \& Schreyer, D. J. (2016). Influence of mechanical properties of alginate-based substrates on the performance of Schwann cells in culture. Journal of Biomaterials Science Polymer Edition, 27(9), 898-915. https://doi.org/10.1080/ 09205063.2016.1170415

Noel, S., Fortier, C., Murschel, F., Belzil, A., Gaudet, G., Jolicoeur, M., ... De Crescenzo, G. (2016). Co-immobilization of adhesive peptides and VEGF within a dextran-based coating for vascular applications. Acta Biomaterialia, 37, 69-82. https://doi.org/10. 1016/j.actbio.2016.03.043

O'Brien, F. J. (2011). Biomaterials \& scaffolds for tissue engineering. Materials Today, 14(3), 88-95. https://doi.org/10.1016/S1369-7021(11)70058-X.

Oelschlaeger, C., Bossler, F., \& Willenbacher, N. (2016). Synthesis, structural and micromechanical properties of 3D hyaluronic acid-based cryogel scaffolds. Biomacromolecules, 17(2), 580-589. https://doi.org/10.1021/acs.biomac.5b01529.

Ohtsubo, K., \& Marth, J. D. (2006). Glycosylation in cellular mechanisms of health and disease. Cell, 126(5), 855-867. https://doi.org/10.1016/j.cell.2006.08.019.

Oliveira, S. M., Pirraco, R. P., Marques, A. P., Santo, V. E., Gomes, M. E., Reis, R. L., .. Mano, J. F. (2016). Platelet lysate-based pro-angiogenic nanocoatings. Acta Biomaterialia, 32, 129-137. https://doi.org/10.1016/j.actbio.2015.12.028.

Oliveira, S. M., Silva, T. H., Reis, R. L., Mano, J. F., Miyazaki, T., Ohtsuki, C., ... Kim, S. E. (2013). Nanocoatings containing sulfated polysaccharides prepared by layer-by-layer assembly as models to study cell-material interactions. Journal of Materials Chemistry B, 1(35), 4406. https://doi.org/10.1039/c3tb20624f.

Orchard, S., Kerrien, S., Abbani, S., Aranda, B., Bhate, J., Bidwell, S., ... Hermjakob, H. (2012). Protein interaction data curation: The International Molecular Exchange (IMEx) consortium. Nature Methods, 9(4), 345-350. https://doi.org/10.1038/nmeth. 1931.

Pacelli, S., Manoharan, V., Desalvo, A., Lomis, N., Jodha, K. S., Prakash, S., ... Ingber, D. E. (2016). Tailoring biomaterial surface properties to modulate host-implant interactions: Implication in cardiovascular and bone therapy. Journal of Materials Chemistry B, Materials for Biology and Medicine, 4(9), 1586-1599. https://doi.org/10.1039/ C5TB01686J.

Pan, T., Song, W., Cao, X., \& Wang, Y. (2016). 3D bioplotting of gelatin/alginate scaffolds for tissue engineering: Influence of crosslinking degree and pore architecture on 
physicochemical properties. Journal of Materials Science \& Technology, 32(9), 889-900. https://doi.org/10.1016/j.jmst.2016.01.007.

Papanas, N., Demetzos, C., Pippa, N., Maltezos, E., \& Tentolouris, N. (2016). Efficacy of a new heparan sulfate mimetic dressing in the healing of foot and lower extremity ulcerations in type 2 diabetes. The International Journal of Lower Extremity Wounds, 15(1), 63-67. https://doi.org/10.1177/1534734616629302.

Park, S., Gildersleeve, J. C., Blixt, O., \& Shin, I. (2013). Carbohydrate microarrays. Chemical Society Reviews, 42(42), 306-312.

Patel, A. K., Celiz, A. D., Rajamohan, D., Anderson, D. G., Langer, R., Davies, M. C., ... Denning, C. (2015). A defined synthetic substrate for serum-free culture of human stem cell derived cardiomyocytes with improved functional maturity identified using combinatorial materials microarrays. Biomaterials, 61, 257-265. https://doi.org/10. 1016/J.BIOMATERIALS. 2015.05.019.

Patla, I., Volberg, T., Elad, N., Hirschfeld-Warneken, V., Grashoff, C., Fässler, R., .. Medalia, O. (2010). Dissecting the molecular architecture of integrin adhesion sites by cryo-electron tomography. Nature Cell Biology, 12(9), 909-915. https://doi.org/ 10.1038/ncb2095.

Pawar, S. N., \& Edgar, K. J. (2012). Alginate derivatization: A review of chemistry, properties and applications. Biomaterials. https://doi.org/10.1016/j.biomaterials. 2012.01.007.

Picheth, G. F., Pirich, C. L., Sierakowski, M. R., Woehl, M. A., Sakakibara, C. N., de Souza, C. F., ... de Freitas, R. A. (2017). Bacterial cellulose in biomedical applications: A review. International Journal of Biological Macromolecules, 104, 97-106. https://doi. org/10.1016/J.IJBIOMAC.2017.05.171.

Pierschbacher, M. D., \& Ruoslahti, E. (1984). Cell attachment activity of fibronectin can be duplicated by small synthetic fragments of the molecule. Nature, 309(5963), 30-33. https://doi.org/10.1038/309030a0.

Place, E. S., Evans, N. D., \& Stevens, M. M. (2009). Complexity in biomaterials for tissue engineering. Nature Materials, 8(6), 457-470. https://doi.org/10.1038/nmat2441.

Plow, E. F., Haas, T. A., Zhang, L., Loftust, J., \& Smith, J. W. (2000). Ligand binding to integrins*. https://doi.org/10.1074/jbc.R000003200.

Prakash Parthiban, S., Rana, D., Jabbari, E., Benkirane-Jessel, N., \& Ramalingam, M. (2017). Covalently immobilized VEGF-mimicking peptide with gelatin methacrylate enhances microvascularization of endothelial cells. Acta Biomaterialia, 51, 330-340. https://doi.org/10.1016/j.actbio.2017.01.046.

Przekora, A., Benko, A., Blazewicz, M., \& Ginalska, G. (2016). Hybrid chitosan/ $\beta-1,3$ glucan matrix of bone scaffold enhances osteoblast adhesion, spreading and proliferation via promotion of serum protein adsorption. Biomedical Materials, 11(4) 045001. https://doi.org/10.1088/1748-6041/11/4/045001.

Puperi, D. S., O'Connell, R. W., Punske, Z. E., Wu, Y., West, J. L., \& Grande-Allen, K. J. (2016). Hyaluronan hydrogels for a biomimetic spongiosa layer of tissue engineered heart valve scaffolds. Biomacromolecules, 17(5), 1766-1775. https://doi.org/10. 1021/acs.biomac.6b00180.

Quan, T., \& Fisher, G. J. (2015). Role of age-associated alterations of the dermal extracellular matrix microenvironment in human skin aging: A mini-review. Gerontology, 61(5), 427-434. https://doi.org/10.1159/000371708.

Rajesh, R., Dominic Ravichandran, Y., Jeevan Kumar Reddy, M., Ryu, S. H., Shanmugharaj, A. M., Feng, Q., ... Gao, J. (2016). Development of functionalized multi-walled carbon nanotube-based polysaccharide-hydroxyapatite scaffolds for bone tissue engineering. RSC Advances, 6(85), 82385-82393. https://doi.org/10. 1039/C6RA16709H.

Ranga, A., Lutolf, M. P., Hilborn, J., \& Ossipov, D. A. (2016). Hyaluronic acid hydrogels formed in situ by transglutaminase-catalyzed reaction. Biomacromolecules, 17(5), 1553-1560. https://doi.org/10.1021/acs.biomac.5b01587.

Raoufi, M., Aslankoohi, N., Mollenhauer, C., Boehm, H., Spatz, J. P., Brüggemann, D., ... Spatz, J. P. (2016). Template-assisted extrusion of biopolymer nanofibers under physiological conditions. Integrative Biology, 8(10), 1059-1066. https://doi.org/10. 1039/C6IB00045B.

Rashidi, H., Yang, J., \& Shakesheff, K. M. (2014). Surface engineering of synthetic polymer materials for tissue engineering and regenerative medicine applications. Biomaterials Science, 2(10), 1318-1331. https://doi.org/10.1039/C3BM60330J.

Reed, S., Lau, G., Delattre, B., Lopez, D. D., Tomsia, A. P., \& Wu, B. M. (2016). Macro- and micro-designed chitosan-alginate scaffold architecture by three-dimensional printing and directional freezing. Biofabrication, 8(1), 015003. https://doi.org/10.1088/17585090/8/1/015003.

Reynolds, P. M., Pedersen, R. H., Riehle, M. O., \& Gadegaard, N. (2012). A dual gradient assay for the parametric analysis of cell-surface interactions. Small, 8(16), 2541-2547. https://doi.org/10.1002/smll.201200235.

Reys, L. L., Silva, S. S., Soares da Costa, D., Oliveira, N. M., Mano, J. F., Reis, R. L., ... Silva, T. H. (2016). Fucoidan hydrogels photo-cross-linked with visible radiation as matrices for cell culture. ACS Biomaterials Science \& Engineering, 2(7), 1151-1161. https://doi.org/10.1021/acsbiomaterials.6b00180.

Rillahan, C. D., \& Paulson, J. C. (2011). Glycan microarrays for decoding the glycome. Annual Review of Biochemistry, 80, 797-823. https://doi.org/10.1146/annurev biochem-061809-152236.

Rinaudo, M. (2006). Chitin and chitosan: Properties and applications. Progress in Polymer Science, 31(January), 603-632. https://doi.org/10.1016/j.progpolymsci.2006.06. 001.

Rinaudo, M. (2008). Main properties and current applications of some polysaccharides as biomaterials. Polymer International, 57(3), 397-430. https://doi.org/10.1002/pi. 2378.

Rodell, C. B., Lee, M. E., Wang, H., Takebayashi, S., Takayama, T., Kawamura, T., Gorman, R. C. (2016). Injectable shear-thinning hydrogels for minimally invasive delivery to infarcted myocardium to limit left ventricular remodeling. Circulation Cardiovascular Interventions, 9(10).

Rodríguez-Vázquez, M., Vega-Ruiz, B., Ramos-Zúñiga, R., Saldaña-Koppel, D. A., \&
Quiñones-Olvera, L. F. (2015). Chitosan and its potential use as a scaffold for tissue engineering in regenerative medicine. BioMed Research International, 2015, 821279. https://doi.org/10.1155/2015/821279.

Rostam, H. M., Singh, S., Salazar, F., Magennis, P., Hook, A., Singh, T., Ghaemmaghami, A. M. (2016). The impact of surface chemistry modification on macrophage polarisation. Immunobiology, 221(11), 1237-1246. https://doi.org/10. 1016/j.imbio.2016.06.010.

Rouwkema, J., \& Khademhosseini, A. (2016). Vascularization and angiogenesis in tissue engineering: Beyond creating static networks. Trends in Biotechnology, 34(9), 733-745. https://doi.org/10.1016/j.tibtech.2016.03.002.

Russo, L., \& Cipolla, L. (2016). Glycomics: New challenges and opportunities in regenerative medicine. Chemistry (Weinheim an Der Bergstrasse, Germany), 22, 13380-13388. https://doi.org/10.1002/chem.201602156.

Ruvinov, E., Freeman, I., Fredo, R., \& Cohen, S. (2016). Spontaneous coassembly of biologically active nanoparticles via affinity binding of heparin-binding proteins to alginate-sulfate. Nano Letters, 16(2), 883-888. https://doi.org/10.1021/acs.nanolett. 5b03598.

Ryan, G., McGarry, P., Pandit, A., \& Apatsidis, D. (2009). Analysis of the mechanical behavior of a titanium scaffold with a repeating unit-cell substructure. Journal of Biomedical Materials Research Part B, Applied Biomaterials, 90B(2), 894-906. https:// doi.org/10.1002/jbm.b.31361.

Sánchez-Sánchez, R., Martínez-Arredondo, E., Martínez-López, V., Melgarejo-Ramírez, Y., Brena-Molina, A., Lugo-Martínez, H., ... Velasquillo, C. (2016). Development of hydrogel with anti-inflammatory properties permissive for the growth of human adipose mesenchymal stem cells. Journal of Nanomaterials, 2016, 1-8. https://doi.org/ 10.1155/2016/8654937.

Schwartz, M. A. (2010). Integrins and extracellular matrix in Mechanotransduction. Cold Spring Harbor Perspectives in Biology, 2(12), a005066. https://doi.org/10.1101/ cshperspect.a005066.

Scognamiglio, F., Travan, A., Borgogna, M., Donati, I., Marsich, E., Bosmans, J. W. A. M., ... Paoletti, S. (2016). Enhanced bioadhesivity of dopamine-functionalized polysaccharidic membranes for general surgery applications. Acta Biomaterialia, 44, 232-242. https://doi.org/10.1016/j.actbio.2016.08.017.

Šebestík, J., Reiniš, M., \& Ježek, J. (2012). Sugar code (glycocode). Biomedical applications of peptide-, glyco- and glycopeptide dendrimers, and analogous dendrimeric structures. Vienna: Springer Vienna23-27. https://doi.org/10.1007/978-3-7091-1206-9_3.

Selhuber-Unkel, C., Erdmann, T., López-García, M., Kessler, H., Schwarz, U. S., \& Spatz, J. P. (2010). Cell adhesion strength is controlled by intermolecular spacing of adhesion receptors. Biophysical Journal, 98(4), 543-551. https://doi.org/10.1016/j.bpj.2009. 11.001.

Selhuber-Unkel, C., López-García, M., Kessler, H., \& Spatz, J. P. (2008). Cooperativity in adhesion cluster formation during initial cell adhesion. Biophysical Journal, 95(11), 5424-5431. https://doi.org/10.1529/biophysj.108.139584.

Shankaran, H., Resat, H., \& Wiley, H. S. (2007). Cell surface receptors for signal transduction and ligand transport: A design principles study. PLoS Computational Biology, 3(6), e101. https://doi.org/10.1371/journal.pcbi.0030101.

Sheikh, Z., Brooks, P., Barzilay, O., Fine, N., \& Glogauer, M. (2015). Macrophages, foreign body giant cells and their response to implantable biomaterials. Materials, 8(9), 5671-5701. https://doi.org/10.3390/ma8095269.

Silva, L. P., Pirraco, R. P., Santos, T. C., Novoa-Carballal, R., Cerqueira, M. T., Reis, R. L., ... Marques, A. P. (2016). Neovascularization induced by the hyaluronic acid-based spongy-like hydrogels degra dation products. ACS Applied Materials \& Interfaces, 8(49), 33464-33474. https://doi.org/10.1021/acsami.6b11684.

Silva, J. M., Custódio, C. A., Reis, R. L., \& Mano, J. F. (2016). Multilayered hollow tubes as blood vessel substitutes. ACS Biomaterials Science \& Engineering, 2(12), 2304-2314. https://doi.org/10.1021/acsbiomaterials.6b00499.

Siqueira, G., Bras, J., \& Dufresne, A. (2010). Cellulosic bionanocomposites: A review of preparation, properties and applications. Polymers, 2(4), 728-765. https://oi.org/ 10.3390/polym2040728.

Skołucka-Szary, K., Ramięga, A., Piaskowska, W., Janicki, B., Grala, M., Rieske, P., ... Piaskowski, S. (2016). Synthesis and physicochemical characterization of chitin dihexanoate - A new biocompatible chitin derivative - In comparison to chitin dibutyrate. Materials Science and Engineering C, 60, 489-502. https://doi.org/10.1016/ j.msec.2015.11.078.

Sobhanadhas, L. S., Kesavan, L., \& Fardim, P. (2018). Topochemical engineering of cellulose-based functional materials. Langmuir, 34(34), 9857-9878. https://doi.org/10. 1021/acs.langmuir.7b04379.

Später, T., Frueh, F. S., Menger, M. D., \& Laschke, M. W. (2017). Potentials and limitations of Integra ${ }^{\otimes}$ flowable wound matrix seeded with adipose tissue-derived microvascular fragments. European Cells \& Materials, 33, 268-278. https://doi.org/10. 22203/eCM.v033a20.

Springer, T. A., Zhu, J., \& Xiao, T. (2008). Structural basis for distinctive recognition of fibrinogen $\gamma \mathrm{C}$ peptide by the platelet integrin $\alpha \mathrm{IIb} \beta 3$. The Journal of Cell Biology, 182(4), 791-800. https://doi.org/10.1083/jcb.200801146.

Stevens, M. M., \& George, J. H. (2005). Exploring and engineering the cell surface interface. Science (New York, NY), 310(November), 1135-1138. https://doi.org/10. 1126/science.1106587.

Stewart, M., \& Hogg, N. (1996). Regulation of leukocyte integrin function: Affinity vs. avidity. Journal of Cellular Biochemistry, 61(4), 554-561. https://doi.org/10.1002/ (SICI)1097-4644(19960616)61:4<554::AID-JCB8 > 3.0.CO;2-N.

Stewart, M., Thiel, M., \& Hogg, N. (1995). Leukocyte integrins. Current Opinion in Cell Biology, 7, 690-696. https://doi.org/10.1016/0955-0674(95)80111-1.

Subramanian, A., Tamayo, P., Mootha, V. K., Mukherjee, S., Ebert, B. L., Gillette, M. A., .. Mesirov, J. P. (2005). Gene set enrichment analysis: A knowledge-based approach for interpreting genome-wide expression profiles. Proceedings of the National Academy of Sciences of the United States of America, 102(43), 15545-15550. https://doi.org/10. 
1073/pnas.0506580102.

Sun, J., \& Tan, H. (2013). Alginate-based biomaterials for regenerative medicine applications. Materials, 6(4), 1285-1309. https://doi.org/10.3390/ma6041285.

Sungkaworn, T., Rieken, F., Lohse, M. J., \& Calebiro, D. (2014). High-resolution spatio temporal analysis of receptor dynamics by single-molecule fluorescence microscopy. Journal of Visualized Experiments: JoVE, 89, e51784. https://doi.org/10.3791/51784.

Szklarczyk, D., Franceschini, A., Wyder, S., Forslund, K., Heller, D., Huerta-Cepas, J., .. von Mering, C. (2015). STRING v10: Protein-protein interaction networks, integrated over the tree of life. Nucleic Acids Research, 43(Database issue), D447-52. https://doi. org/10.1093/nar/gku1003.

Thakur, A., Jaiswal, M. K., Peak, C. W., Carrow, J. K., Gentry, J., Dolatshahi-Pirouz, A., ... Khademhosseini, A. (2016). Injectable shear-thinning nanoengineered hydrogels for stem cell delivery. Nanoscale, 8(24), 12362-12372. https://doi.org/10.1039/ C6NR02299E.

The Gene Ontology Consortium (2017). Expansion of the gene ontology knowledgebase and resources. Nucleic Acids Research, 45(D1), D331-D338. https://doi.org/10.1093/ nar/gkw1108.

The UniProt Consortium (2017). UniProt: The universal protein knowledgebase. Nucleic Acids Research, 45(D1), D158-D169. https://doi.org/10.1093/nar/gkw1099.

Torgbo, S., \& Sukyai, P. (2018). Bacterial cellulose-based scaffold materials for bone tissue engineering. Applied Materials Today, 11, 34-49. https://doi.org/10.1016/J. APMT.2018.01.004.

Van Bael, S., Kerckhofs, G., Moesen, M., Pyka, G., Schrooten, J., \& Kruth, J. P. (2011). Micro-CT-based improvement of geometrical and mechanical controllability of selective laser melted Ti6Al4V porous structures. Materials Science and Engineering A, 528(24), 7423-7431. https://doi.org/10.1016/j.msea.2011.06.045.

van Eck, N. J., \& Waltman, L. (2010). Software survey: VOSviewer, a computer program for bibliometric mapping. Scientometrics, 84(2), 523-538. https://doi.org/10.1007/ s11192-009-0146-3.

van Eck, N. J., \& Waltman, L. (2014). Visualizing bibliometric networks. Measuring scholarly impact. Cham: Springer International Publishing285-320. https://doi.org/10.1007/ 978-3-319-10377-8_13.

Van Nieuwenhove, I., Salamon, A., Peters, K., Graulus, G.-J., Martins, J. C., Frankel, D., ... Dubruel, P. (2016). Gelatin- and starch-based hydrogels. Part A: Hydrogel development, characterization and coating. Carbohydrate Polymers, 152, 129-139. https:// doi.org/10.1016/j.carbpol.2016.06.098.

Varki, A., Cummings, R. D., Esko, J. D., Stanley, P., Hart, G. W., Aebi, M., ... Seeberger, P. H. (2015). Essentials of glycobiology. Essentials of glycobiology. Cold Spring Harbor Laboratory Press.

Varki, A., \& Gagneux, P. (2015). Biological functions of glycans. Essentials of glycobiology. Cold Spring Harbor Laboratory Presshttps://doi.org/10.1101/GLYCOBIOLOGY.3E. 007.

Velnar, T., Bailey, T., \& Smrkolj, V. (2009). The wound healing process: An overview of the cellular and molecular mechanisms. The Journal of International Medical Research, 37(375), 1528-1542.

Waghmare, V. S., Wadke, P. R., Dyawanapelly, S., Deshpande, A., Jain, R., \& Dandekar, P. (2018). Starch based nanofibrous scaffolds for wound healing applications. Bioactive Materials, 3(3), 255-266. https://doi.org/10.1016/J.BIOACTMAT.2017.11.006.

Wagner, M. S., \& Castner, D. G. (2001). Characterization of adsorbed protein films by time-of-flight secondary ion mass spectrometry with principal component analysis. Langmuir, 17(15), 4649-4660. https://doi.org/10.1021/la001209t.

Wan, A. C. A., \& Tai, B. C. U. (2013). CHITIN - A promising biomaterial for tissue engineering and stem cell technologies. Biotechnology Advances. https://doi.org/10. 1016/j.biotechadv.2013.09.007 Elsevier.

Wang, D. (2014). Glyco-epitope diversity: An evolving area of glycomics research and biomarker discovery. Journal of Proteomics \& Bioinformatics, 7(2), https://doi.org/10. 4172/jpb.10000e24.

Wang, Y., Zhao, Y., Sun, C., Hu, W., Zhao, J., Li, G., ... Gu, X. (2016). Chitosan degradation products promote nerve regeneration by stimulating schwann cell proliferation via miR-27a/FOXO1 Axis. Molecular Neurobiology, 53(1), 28-39. https:// doi.org/10.1007/s12035-014-8968-2.

Wilhelm, M., Schlegl, J., Hahne, H., Gholami, A. M., Lieberenz, M., Savitski, M. M., Kuster, B. (2014). Mass-spectrometry-based draft of the human proteome. Nature, 509(7502), 582-587. https://doi.org/10.1038/nature13319.

Williams, C., Quinn, K. P., Georgakoudi, I., \& Black, L. D. (2014). Young developmental age cardiac extracellular matrix promotes the expansion of neonatal cardiomyocytes in vitro. Acta Biomaterialia, 10(1), 194-204. https://doi.org/10.1016/j.actbio.2013. 08.037 .

Williams, D. F. (2017). A paradigm for the evaluation of tissue-engineering biomaterials and templates. Tissue Engineering Part C, Methods, 23(12), 926-937. https://doi.org/ 10.1089/ten.tec.2017.0181.

Wu, D., Samanta, A., Srivastava, R. K., \& Hakkarainen, M. (2017). Starch-derived nanographene oxide paves the way for electrospinnable and bioactive starch scaffolds for bone tissue engineering. Biomacromolecules, 18(5), 1582-1591. https://doi.org/ 10.1021/acs.biomac.7b00195.

Wu, H., Wang, H., Cheng, F., Xu, F., Cheng, G., Dong, H., ... Cheng, G. (2016). Synthesis and characterization of an enzyme-degradable zwitterionic dextran hydrogel. RSC Advances, 6(37), 30862-30866. https://doi.org/10.1039/C6RA00550K.

Xiong, J.-P., Stehle, T., Diefenbach, B., Zhang, R., Dunker, R., Scott, D. L., ... Arnaout, M. A. (2001). Crystal structure of the extracellular segment of integrin $\alpha \mathrm{V} \beta 3$. Science, 294(5541), 339-345. https://doi.org/10.1126/science.1069040.

Xiong, J.-P., Stehle, T., Zhang, R., Joachimiak, A., Frech, M., Goodman, S. L., ... Arnaout, M. A. (2002). Crystal structure of the extracellular segment of integrin $\alpha \mathrm{V} \beta 3$ in complex with an Arg-Gly-Asp ligand. Science (New York, NY), 296(5565), 151-155. https://doi.org/10.1126/science.1069040.

Xu, W., Wang, X., Sandler, N., Willför, S., \& Xu, C. (2018). Three-dimensional printing of wood-derived biopolymers: A review focused on biomedical applications. ACS Sustainable Chemistry \& Engineering, 6(5), 5663-5680. https://doi.org/10.1021/ acssuschemeng.7b03924.

Yamada, K. M. (1991). Adhesive recognition sequences. The Journal of Biological Chemistry, 266(20), 12809-12812.

Yang, J., \& Han, C. (2016). Mechanically viscoelastic properties of cellulose nanocrystals skeleton reinforced hierarchical composite hydrogels. ACS Applied Materials \& Interfaces, 8(38), 25621-25630. https://doi.org/10.1021/acsami.6b08834.

Yang, J., Mei, Y., Hook, A. L., Taylor, M., Urquhart, A. J., Bogatyrev, S. R., ... Alexander, M. R. (2010). Polymer surface functionalities that control human embryoid body cell adhesion revealed by high throughput surface characterization of combinatorial material microarrays. Biomaterials, 31(34), 8827-8838. https://doi.org/10.1016/j. biomaterials.2010.08.028.

Yang, J., Rose, F. R. A. J., Gadegaard, N., \& Alexander, M. R. (2009). A high-throughput assay of cell-surface interactions using topographical and chemical gradients. Advanced Materials, 21(3), 300-304. https://doi.org/10.1002/adma.200801942.

Yang, Y., Wang, X., Yang, F., Shen, H., \& Wu, D. (2016). A universal soaking strategy to convert composite hydrogels into extremely tough and rapidly recoverable doublenetwork hydrogels. Advanced Materials, 28(33), 7178-7184. https://doi.org/10 1002/adma.201601742.

Ye, X., Li, S., Chen, X., Zhan, Y., \& Li, X. (2017). Polyethylenimine/silk fibroin multilayers deposited nanofibrics for cell culture. International Journal of Biological Macromolecules, 94, 492-499. https://doi.org/10.1016/j.ijbiomac.2016.10.047.

You, J., Cao, J., Zhao, Y., Zhang, L., Zhou, J., \& Chen, Y. (2016). Improved mechanical properties and sustained release behavior of cationic cellulose nanocrystals reinforeced cationic cellulose injectable hydrogels. Biomacromolecules, 17(9), 2839-2848. https://doi.org/10.1021/acs.biomac.6b00646.

Younes, I., \& Rinaudo, M. (2015). Chitin and chitosan preparation from marine sources. Structure, properties and applications. Marine Drugs, 13(3), 1133-1174. https://doi. org $/ 10.3390 / \mathrm{md} 13031133$.

Zeng, Q., Qin, J., Yin, X., Liu, H., Zhu, L., Dong, W., ... Zhang, S. (2016). Preparation and hemocompatibility of electrospun O-carboxymethyl chitosan/PVA nanofibers. Journal of Applied Polymer Science, 133(26), https://doi.org/10.1002/app.43565.

Zerbino, D. R., Achuthan, P., Akanni, W., Amode, M. R., Barrell, D., Bhai, J., ... Flicek, P. (2018). Ensembl 2018. Nucleic Acids Research, 46(D1), D754-D761. https://doi.org/ 10.1093/nar/gkx1098.

Zhang, D., \& Kilian, K. A. (2014). Peptide microarrays for the discovery of bioactive surfaces that guide cellular processes: A single step azide-Alkyne "click" chemistry approach. Journal of Materials Chemistry B, Materials for Biology and Medicine, 2(27), 4280-4288. https://doi.org/10.1039/C4TB00375F.

Zhang, Y., Ye, L., Cui, J., Yang, B., Sun, H., Li, J., ... Yao, F. (2016). A biomimetic poly (vinyl alcohol)-Carrageenan composite scaffold with oriented microarchitecture. ACS Biomaterials Science \& Engineering, 2(4), 544-557. https://doi.org/10.1021/ acsbiomaterials. $5 \mathrm{~b} 00535$.

Zhao, B., Tumaneng, K., \& Guan, K.-L. (2011). The Hippo pathway in organ size control, tissue regeneration and stem cell self-renewal. Nature Cell Biology, 13(8), 877-883. https://doi.org/10.1038/ncb2303.

Zhao, L., Li, J., Zhang, L., Wang, Y., Wang, J., Gu, B., ... Wu, Z. (2016). Preparation and characterization of calcium phosphate/pectin scaffolds for bone tissue engineering. RSC Advances, 6(67), 62071-62082. https://doi.org/10.1039/C6RA07800A.

Zhou, W., Liu, G., Yang, S., \& Ye, S. (2016). Investigation for effects of cyclical dynamic compression on matrix metabolite and mechanical properties of chondrocytes cultured in alginate. Journal of Hard Tissue Biology, 25(4), 351-356. https://doi.org/10. 2485/jhtb.25.351.

Zhu, H., Luo, W., Ciesielski, P. N., Fang, Z., Zhu, J. Y., Henriksson, G., ... Hu, L. (2016) Wood-derived materials for green electronics, biological devices, and energy applications. Chemical Reviews, 116(16), 9305-9374. https://doi.org/10.1021/acs. chemrev.6b00225. 